\title{
EXPERIMENTAL STUDIES ON THE GLOBAL STABILITY OF CONCRETE SANDWICHED DOUBLE STEEL TUBULAR COLUMNS
}

\author{
Mashudha Sulthana U., ${ }^{1, *}$ and Arul Jayachandran S. ${ }^{2}$
}

\author{
${ }^{I}$ Post Doctoral Research Scholar, Department of Civil Engineering, Indian Institute of Technology Madras, Chennai-600036, India. \\ ${ }^{2}$ Professor, Department of Civil Engineering, Indian Institute of Technology Madras, Chennai-600036, India. \\ (Corresponding author: Email: mashudha@gmail.com)
}

\section{A B S T R A C T}

In improving the ductility and fire-resistance properties of framed structural systems, concrete sandwiched double steel tubular columns (CSDST) are found to be advantageous over concrete filled steel tubular columns (CFST), particularly when the columns are slender. However, a comprehensive understanding of the long column behaviour of CSDST is not fully developed. In this paper, experimental studies on the global stability aspects of CFDST columns is presented. Axial compression tests are carried out on twelve CSDST specimens with two CFST as benchmark specimens having nondimensional member slenderness value around unity. Shape of the inner and outer steel tubes, hollowness ratio and concrete strength are selected as primary parameters for the experimental study. Comparing the experimental results of CSDST with CFST, it is found that the buckling capacity of CSDST is lesser than CFST. The degree of stability in CSDST is directly proportional to the hollowness ratio, irrespective of the cross-section shape and sandwiched concrete strength. The effective flexural rigidity of the specimens derived from the experimental results is reported here, which reiterates the inverse relation of hollowness ratio to the column instability. An average over-strength of around $12 \%$ for square and $20 \%$ for circular specimens is observed in the test axial capacities when compared to the code specifications (ANSI/AISC 360(16) and EN 1994-1-1 2004). Low initial global imperfection ( $\approx \mathrm{L} / 7000)$ in the specimens has led to the over-strength in test axial capacities. It is concluded that the code axial capacity equation for long column CFST (ANSI/AISC 360(16) and EN 1994-1-1 2004) can be adopted for CSDST long columns. However, these code equations are comparatively less conservative for CSDST with less than $50 \%$ hollowness.

\section{ART I C LE H I S T O RY}

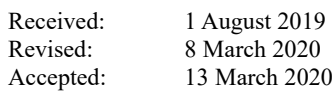

\section{K E Y W O R D S}

Composite columns

CFDST;

global stability;

confinement effect;

initial imperfection;

hollowness ratio

\section{Introduction}

In modern-day construction, concrete sandwiched double steel tubular column (CSDST) is preferred for enhancing the ductility and fire resistance properties in structural systems [3], [4], [5] in addition to the improved flexural rigidity. They also exhibit good structural performance under blast loads [6], [7]. Most of the research conducted towards the development of design framework for CSDST compares its behaviour with concrete filled steel tubes (CFST) considering the load transfer mechanism within the cross-section (Figure 1). Even though there is a visible similarity between these two crosssections, apparent differences in the concrete confinement due to hollowness effect are confirmed through experiments [8], [9]. The existing literature has considerable experimental works on short column CSDST that lead to a reasonable quantification of the cross-section capacity [8]-[15]. However, experimental data available on long column CSDST are limited and inconclusive on its global stability aspects.

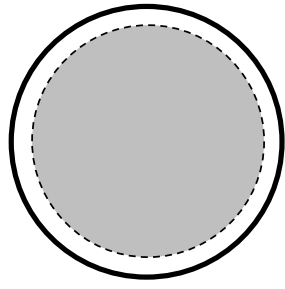

(a)

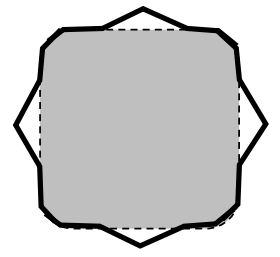

(c)

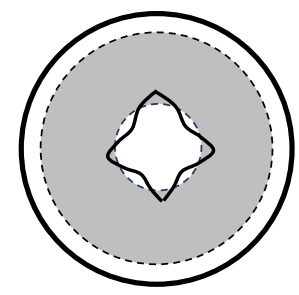

(b)

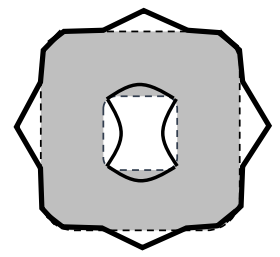

(d)
Fig. 1 Comparison of deformed CFST and CSDST cross-sections under axial compression. (a) CFST-circular; (b) CSDST-CC; (c) CFST-square; (d) CSDST-SS
Slender column CSDST specimens with inner and outer circular steel tubes (CSDST-CC) have been experimentally studied by Tao et al.[8], wherein only two numbers of specimens are axially loaded. The non-dimensional member slenderness $(\lambda)$ of the specimens is around 0.66 and the concrete compressive strength is $46.3 \mathrm{~N} / \mathrm{mm}^{2}$. The code predictions (ANSI/AISC 360(16) and EN 1994-1-1 2004) are found to be marginally over-estimating the actual capacity of the specimens. Essopjee and Dundu [16] tested twenty two CSDST-CC columns in the slenderness range from 0.5 to 0.8 , with concrete cube compressive strength around $30 \mathrm{~N} / \mathrm{mm}^{2}$. The test findings have shown EN 1994-1-1 (2004) (EC4) [1] curve $a$ to be un-conservative for CSDST columns in inelastic buckling range and a modified column curve has been proposed [16] as shown in Figure 2. However, the proposed column strength curve is not applicable for slenderness region beyond the reported test data range. Romero et al. [4] conducted axial compressive tests on long column $(\lambda \approx 0.8)$ CSDST-CC under ambient and elevated temperatures. The study finds the CSDST cross-section to be the most suitable choice for fire resistance, albeit the over estimation in the capacity prediction using EC4 under ambient conditions. The axial compressive tests have been conducted on CSDST with inner and outer square steel tubes (CSDST-SS) with hollowness and non-dimentional slenderness ratio around 0.35 and 0.75 , respectively [17] Unconservative axial capacity predictions have been observed on using ANSI/AISC 360(16) and EN 1994-1-1 (2004). The above experimental studies have reported the buckling strength of CSDST slender column as overpredicted by code provisions available for CFST. However, a comprehensive justification for the same is not found. Moreover, these studies have not evaluated the parameters that distincts CSDST from CFST like hollowness ratio etc. Further, these reported test data have not presented the initial imperfection condition of the specimens, which is an important factor for using the column curves in ANSI/AISC 360(16) and EN 1994-1-1 (2004), particularly for the inelastic region of column slenderness $(0.3<\lambda<1.4)$ Galambos and Surovek [18]. 


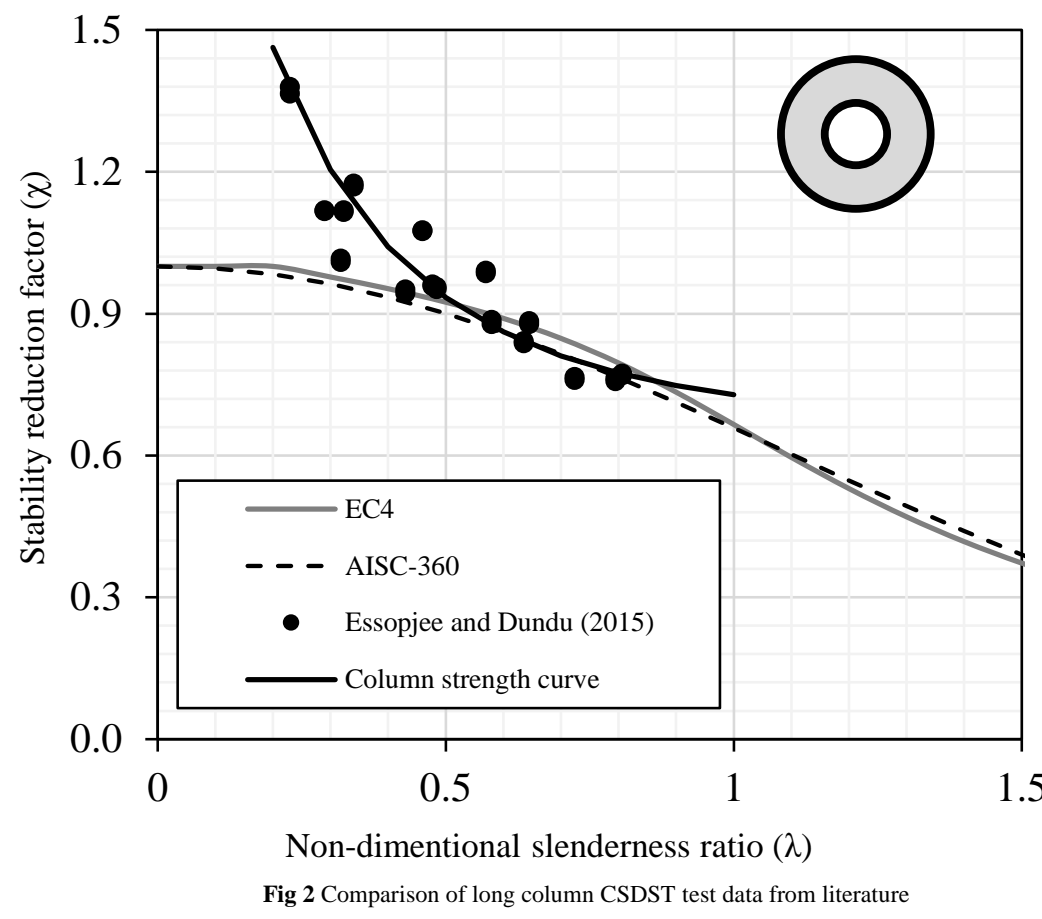

The present research aims to expand the experimental database of CSDST slender columns in higher slenderness range (around unity), where the current literature is inadequate. Parameters that distincts CSDST from CFST crosssections are selected for the study. In this paper, the axial compression test results of twelve CSDST and two CFST long columns with hollowness ratio as a primary parameter is presented. The shape of the steel tubes (square and circular) and concrete strength (normal and high strength) are selected as subset parameters in the experimental study. The test ultimate load is compared with the code equations (ANSI/AISC 360(16); EN 1994-1-1 2004) to examine the applicability of the current methods in the design of long column CSDST. The effective flexural rigidity $\left(E I_{e f f}\right)$ of the specimens that defines the member and system stability of the composite column is derived from the experimental results and presented here. The significance of inner steel tube in predicting the buckling capacity and effective flexural rigidity of CSDST long column is discussed through experimental findings.

\section{Experimental program}

\subsection{Geometric and material properties of the specimens}

The cross-section of fourteen specimens selected for the experimental study is widely divided based on the shape of the outer steel tube, as square and circular (Figure 3). They are in turn classified based on the hollowness ratio $\left(h_{r}=D_{i} /\left(D_{o}-2 t_{o}\right)\right)$ of the cross-sections, and the compressive strength of the infill concrete. The unique ID assigned for each specimen contains details about the parameters considered in the study, namely, the cross-section shape, hollowness ratio and concrete strength. The representation of the specimen ID is shown in Figure 3. Three types of hollowness ratios $\left(h_{r}\right)$ are selected for CSDST specimens $(0.2,0.5$ and 0.7$)$. The maximum hollowness ratio is restricted to 0.7 due to practical difficulties in ensuring concrete flow through the annular space while concreting. The minimum value of 0.2 is selected based on the commercially available minimum dimension of the steel tube. The intermediate hollowness ratio of 0.5 is considered, as the effective axial stiffness of this cross-section is same as the corresponding CFST. Normal strength $\left(40 \mathrm{~N} / \mathrm{mm}^{2}\right)$ and high strength $\left(80 \mathrm{~N} / \mathrm{mm}^{2}\right)$ concrete are selected to understand the effect of concrete strength on the long column behaviour. Length of all test specimens is $3.6 \mathrm{~m}$, and the cross-section dimensions are selected (Table 1) such that the non-dimensional member slenderness ratio $(\lambda)$ will be around unity and specimens fail by global buckling. Compact crosssections are selected, where $D / t<0.15\left(E_{s} / f_{y}\right)$ for circular tubes, and $B / t<$ $2.26 \sqrt{ }\left(E_{s} / f_{y}\right)$ for square tubes, to avoid local and interaction buckling effects. The steel tubes have been manufactured by cold-rolling and cold-forming process and a finishing seam is developed by high frequency induction weld. As they are supplied in $6 \mathrm{~m}$ length, they are cut into the required length using an automated cutting blade, while ensuring a perpendicular plane of cut across the longitudinal axis of the steel tube. The actual dimensions measured from each steel tube is shown in Table 1 .

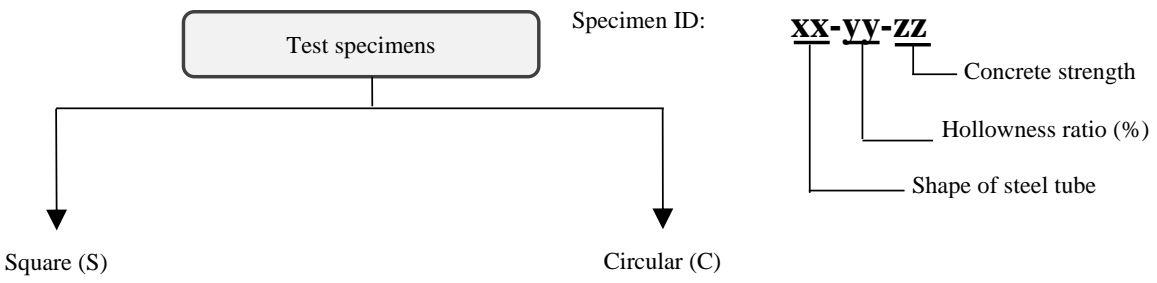

(7 specimens)

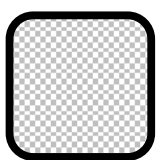

S- $0-40$

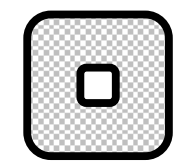

SS-20-40

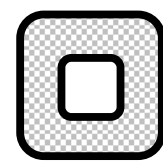

SS-50-40

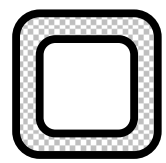

SS-70-40

(7 specimens)

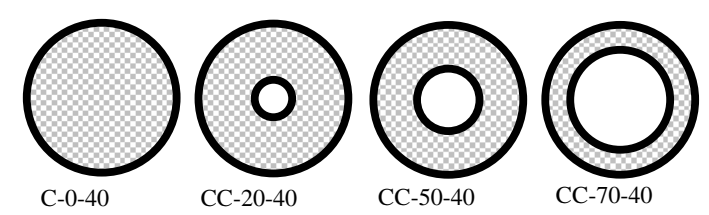

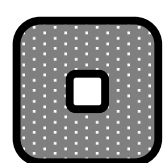

SS-20-80

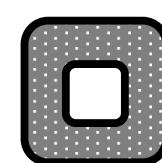

SS-50-80

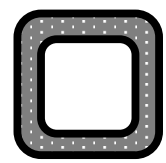

SS-70-80

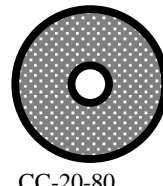

CC-20-80

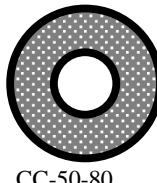

CC-50-80

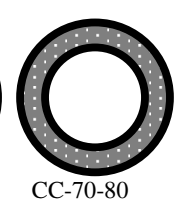

CC-70-80

Fig 3 Classification of test specimens in the present study 
Three numbers of tension coupons are prepared from each steel tube and tested as per ASTM-E8/E8M (2009) [19]. The yield strength of the steel tube, derieved from the coupon test, is well above the nominal strength of 310 $\mathrm{N} / \mathrm{mm}^{2}$, which is typical for cold-rolled and cold-formed steel. The tension coupon from circular steel tubes underwent a bending deformation along its length that is indicative of residual stress release, while cutting the steel tubes to make coupons. Since the total tensile load applied in the coupon test is inclusive of correcting this bending deformation, residual stresses are not measured separately. The average mechanical properties from the coupon test is presented in Table 2. The average modulus of elasticity and Poisson's ratio of the steel tubes is $2 \times 10^{5} \mathrm{MPa}$ and 0.28 , respectively.

Table 1

Geometric properties of steel tubes selected for the test

\begin{tabular}{|c|c|c|c|c|c|c|c|c|}
\hline \multirow[b]{2}{*}{ Sp. ID } & \multicolumn{2}{|c|}{ Nominal size } & \multicolumn{4}{|c|}{ Measured size } & \multirow[b]{2}{*}{$D_{o} / t_{o}$} & \multirow[b]{2}{*}{$D_{i} / t_{i}$} \\
\hline & $\begin{array}{l}\text { Outer tube } \\
\qquad(\mathrm{mm})\end{array}$ & $\begin{array}{c}\text { Inner tube } \\
\quad(\mathrm{mm})\end{array}$ & $\begin{array}{c}D_{o} \\
(\mathrm{~mm})\end{array}$ & $\begin{array}{c}t_{o} \\
(\mathrm{~mm})\end{array}$ & $\begin{array}{c}D_{i} \\
(\mathrm{~mm})\end{array}$ & $\begin{array}{c}t_{i} \\
(\mathrm{~mm})\end{array}$ & & \\
\hline$S-0-40$ & $150 \times 150 x 6$ & - & 150 & 6.08 & - & - & 24.67 & - \\
\hline SS-20-40 & $150 \times 150 \times 6$ & $32 \times 32 \times 2$ & 150.65 & 6.16 & 32 & 2 & 24.46 & 16.00 \\
\hline SS-50-40 & $150 \times 150 \times 6$ & $72 \times 72 \times 4$ & 150.62 & 6.12 & 72.22 & 4 & 24.61 & 18.06 \\
\hline SS-70-40 & $150 \times 150 \times 6$ & $100 \times 100 \times 4$ & 149.88 & 6.08 & 100.3 & 4.06 & 24.65 & 24.71 \\
\hline SS-20-80 & $150 \times 150 \times 6$ & $32 \times 32 \times 2$ & 151.05 & 6.1 & 32 & 2 & 24.76 & 16.00 \\
\hline SS-50-80 & $150 \times 150 \times 6$ & $72 \times 72 \times 4$ & 150.35 & 6.14 & 72.52 & 3.96 & 24.49 & 18.31 \\
\hline SS-70-80 & $150 \times 150 \times 6$ & $100 \times 100 \times 4$ & 149.98 & 6.08 & 100.3 & 3.94 & 24.67 & 25.46 \\
\hline C- $0-40$ & NB-150x5.4 & - & 166.06 & 5.18 & - & - & 32.06 & - \\
\hline CC- $-20-40$ & NB-150x5.4 & NB- $25 x 4$ & 166.34 & 5.24 & 33.7 & 4 & 31.74 & 8.43 \\
\hline CC-50-40 & NB-150x5.4 & NB-65x3.6 & 166 & 5.04 & 76.66 & 3.58 & 32.94 & 21.41 \\
\hline CC-70-40 & NB-150x5.4 & NB-100x5.4 & 165.84 & 5.06 & 114.1 & 5.2 & 32.77 & 21.94 \\
\hline CC-20-80 & NB-150x5.4 & NB- $25 \times 4$ & 166.36 & 5.22 & 33.7 & 4 & 31.87 & 8.43 \\
\hline CC-50-80 & NB-150x5.4 & NB-65x3.6 & 165.86 & 5.24 & 76.74 & 3.58 & 31.65 & 21.44 \\
\hline CC-70-80 & NB-150x5.4 & NB-100x5.4 & 166.32 & 5.24 & 114.2 & 5.22 & 31.74 & 21.88 \\
\hline
\end{tabular}

Self-compacting concrete having a slump value of around $600-700 \mathrm{~mm}$ (from concrete flow test) is used for filling the steel tubes. Steel tubes are taken to a ready mix concrete plant for concreting due to logistical constraints. Normal and high strength concrete mix is designed for $40 \mathrm{~N} / \mathrm{mm}^{2}$ and $80 \mathrm{~N} / \mathrm{mm}^{2}$ respectively, and the mix design quantities of concrete ingredients is tabulated in Appendix-I. Separate batches of concrete is prepared for filling each specimen, and three sets of $150 \mathrm{~mm}$ concrete cubes are cast from each batch for material characterization. The compressive strength of the concrete cube is tested as per IS:516 (1959) [20] (Indian Standard that is in line with BSI and ASTM standards) on 28-day and on the day of testing, which are found to be almost the same. The mean compressive strength of concrete on the day of testing for the respective specimens is presented in Table 2. Typical nominal coarse aggregate size used for concreting is $12 \mathrm{~mm}$, except for CSDST with $70 \%$ hollowness, where $6 \mathrm{~mm}$ is used to facilitate free flow while concreting.

Table 2

Mechanical properties of steel and concrete used in the test specimens

\begin{tabular}{cccccc}
\hline Sp. ID & $\begin{array}{c}f_{y o} \\
\left(\mathrm{~N} / \mathrm{mm}^{2}\right)\end{array}$ & $\begin{array}{c}f_{y i} \\
\left(\mathrm{~N} / \mathrm{mm}^{2}\right)\end{array}$ & $\begin{array}{c}f_{u o} \\
\left(\mathrm{~N} / \mathrm{mm}^{2}\right)\end{array}$ & $\begin{array}{c}f_{u i} \\
\left(\mathrm{~N} / \mathrm{mm}^{2}\right)\end{array}$ & $\begin{array}{c}f_{c k} \\
\mathrm{~N} / \mathrm{mm}^{2}\end{array}$ \\
\hline S-0-40 & 401 & - & 445 & - & 51.28 \\
SS-20-40 & 400 & 400 & 445 & 450 & 51.28 \\
SS-50-40 & 400 & 400 & 440 & 450 & 54.83 \\
SS-70-40 & 405 & 400 & 430 & 450 & 57.5 \\
SS-20-80 & 400 & 400 & 450 & 450 & 89.02 \\
SS-50-80 & 390 & 400 & 430 & 450 & 84.95 \\
SS-70-80 & 390 & 400 & 428 & 450 & 87.25 \\
C-0-40 & 522 & - & 581 & - & 58.61 \\
CC-20-40 & 523 & 519 & 570 & 561 & 57.94 \\
CC-50-40 & 518 & 521 & 550 & 561 & 55.5 \\
CC-70-40 & 521 & 520 & 560 & 561 & 60.61 \\
CC-20-80 & 523 & 519 & 568 & 561 & 84.95 \\
CC-50-80 & 519 & 520 & 560 & 561 & 85.47 \\
CC-70-80 & 519 & 520 & 551 & 561 & 84.36 \\
\hline
\end{tabular}

2.2. Preparation of test specimens
After the steel tubes are cut for the required length, one end of the outer steel tube (for each specimen) is welded (fillet type) to a $20 \mathrm{~mm}$ thick mild steel base plate, ensuring the perpendicularity between the tube and the base plate. The initial imperfection profile of the outer steel tube is measured by placing it on a lathe bed that has an accurate horizontal orientation. The imperfections are measured using a laser beam arrangement at an interval of $100 \mathrm{~mm}$ along the length of the specimen, and they are found to be mostly localized with a maximum offset of $2 \mathrm{~mm}$. Since the problem at hand is sensitive for global imperfections, a moving average of the measured imperfections is presented in Figure 4 that represents the initial global profile of the outer steel tube. Typical global imperfection profile of a square and circular steel tube is given in Figure 4, with a maximum bow in the order of $L / 7000$. The outer steel tube profile represents the initial overall profile of the test specimen.

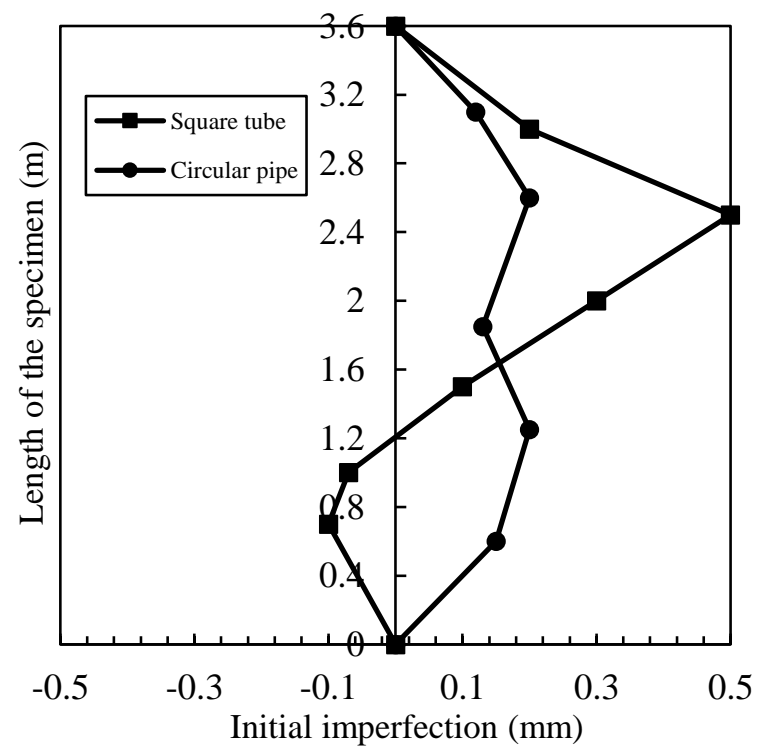

Fig. 4 Initial imperfection in the steel tubes 
In CSDST specimen preparation, to ensure the concentricity between the inner and outer steel tubes during concreting, the inner steel tube is welded to steel spacer bars at both ends of the specimen (Figure 5). At the concreting end of the specimen, hollow space in the inner steel tube is covered to avoid accidental intrusion of concrete. Specimens are concreted from the top in upright position at the ready mix concrete plant (Figure 6). All specimens except SS-70-40 are successfully filled with concrete. The inner steel tube orientation in SS-70-40 is slightly disturbed while concreting, and the annular space became insufficient for a smooth concrete flow. The specimens are kept in the plant for two days, until complete hardening of concrete, and later shifted to Structural Engineering Laboratory, IIT Madras. The specimens are allowed to air cure for 28 days along with their respective concrete cubes. Towards the end of the curing period, the specimens are prepared for the testing process. The concreted end of the specimen is inspected for concrete shrinkage. The excess concrete at the tube edge is removed, and cement-sand mortar in the ratio of 1:1 is applied to even out the undulations. The specimen end prepared with mortar is fillet-welded to a $20 \mathrm{~mm}$ mild steel plate, similar to the other end. The surface of the outer steel tube is cleaned thoroughly before testing and strain gauges are pasted at locations specified in the instrumentation scheme (Figure 9).

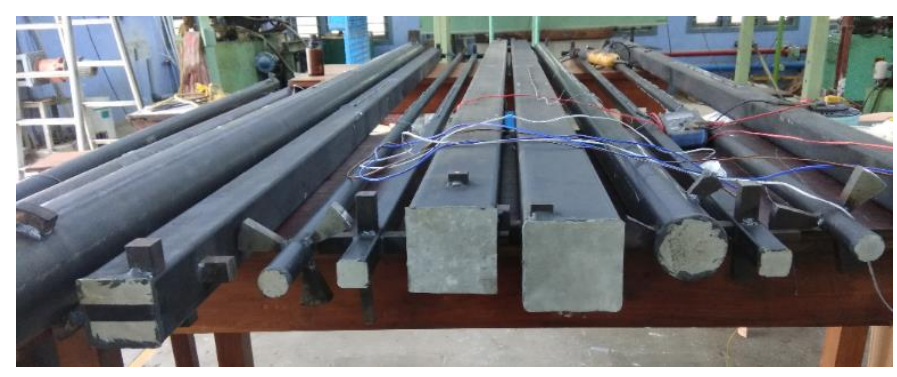

Fig. 5 Inner steel tubes with spacer bars and dummied concreting end

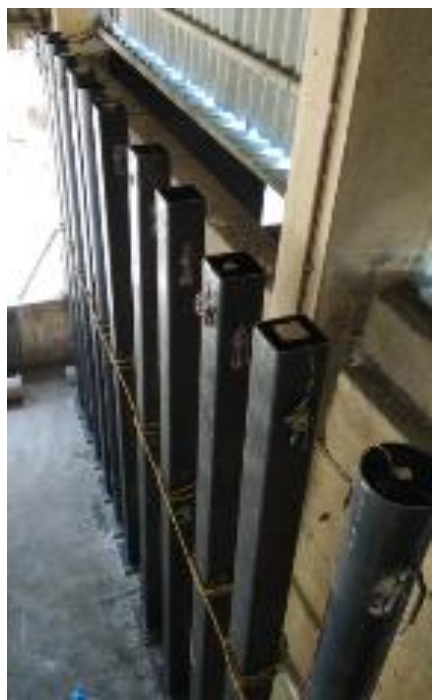

Fig. 6 Concreting of the specimens

\subsection{Test set-up, instrumentation and loading}

Axial compression test is conducted in a $6000 \mathrm{kN}$ self-equilibriating testing frame, and specimens are loaded using a $5000 \mathrm{kN}$ hydraulic jack. Even though the set-up is load-controlled in nature, behaviour of the specimen beyond the ultimate load could be measured by manual control of the machine, for few points in the post-peak range. The schematic diagram of the test set-up is shown in Figure 7. The test specimens are fillet-welded to mild steel plates of size $250 \times 300 \times 20 \mathrm{~mm}$ on both the ends, to ensure uniform distribution of axial load across the cross-section. Pin-pin boundary condition is designed for the test set-up by fabricating roller bar and tapered plates arrangement as shown in the schematic diagram (Figure 7). Buckling of the specimen is constrained to single axis of cross-section by providing a roller bar as hinge supports. Before mounting the specimen, roller bars are applied with grease to avoid load losses due to friction (Figure 8). Sufficiently thick steel end plates $(60 \mathrm{~mm})$ with higher grade (EN8) is chosen to reduce end plate deformation upon load transfer.

Linear variable displacement transducers (LVDTs) and linear strain gauges are used for measuring the specimen deformation under loaded condition. Since the specimen buckling is constrained to single axis, instrumentation is located in the allowable buckling plane alone. Two numbers of LVDTs to measure axial deformation and three numbers of LVDTs for measuring lateral displacement are placed at the locations as indicated in Figure 9(a). Strain gauges are pasted on either faces of the specimen across the buckling axis at the mid-height to measure longitudinal as well as circumferencial strains (Figure 9b). Linear strain gauges are also pasted in the longitudinal axis of inner steel tube, to study a probable non-composite action between the steel tubes in CSDST. A $5000 \mathrm{kN}$ load cell is placed as shown in the test set-up, and it is synced with LVDT and strain gauge readings. The instrumentation is connected to a data logger for continuous recording of measurements. The specimens are axially compressed by the hydraulic jack till they undergo a complete buckling failure. A typical failure mode of the test specimens is presented in the photograph of a representative specimen (Figure 10). Specimens are failed by global buckling under axial compression, as expected in the pre-processing of this experimental study. The failure mode of the specimen is compared with its corresponding initial configuration before loading (Figure 10a). The deformed configuration of the specimen shows smooth rotation at the pin ends (i.e. no frictional load losses at the pin supports).

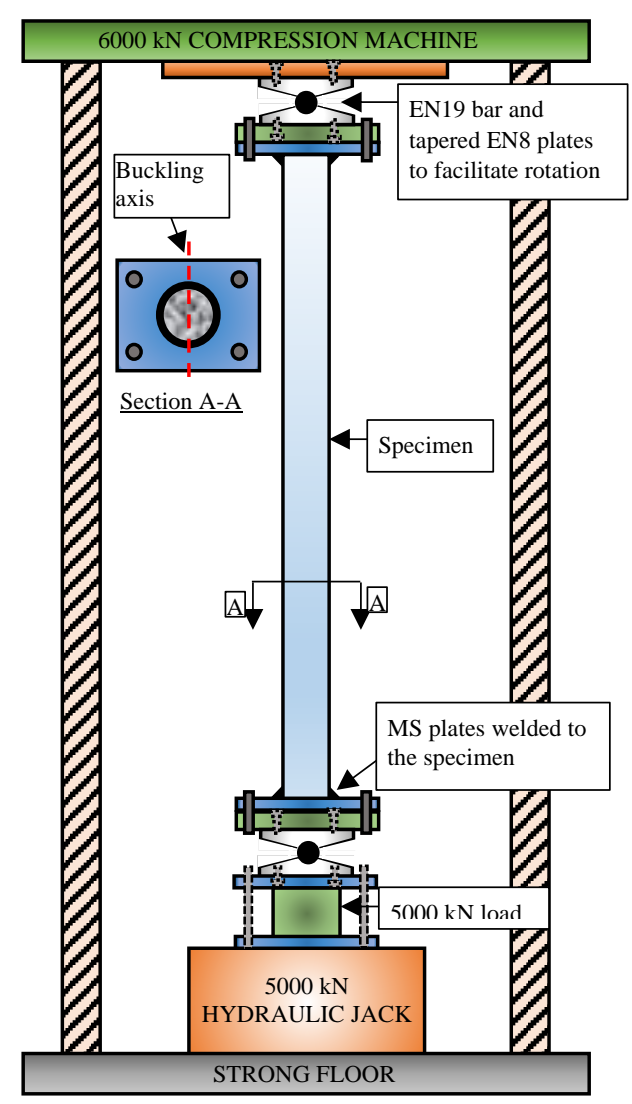

Fig 7 Schematic diagram of the test set-up

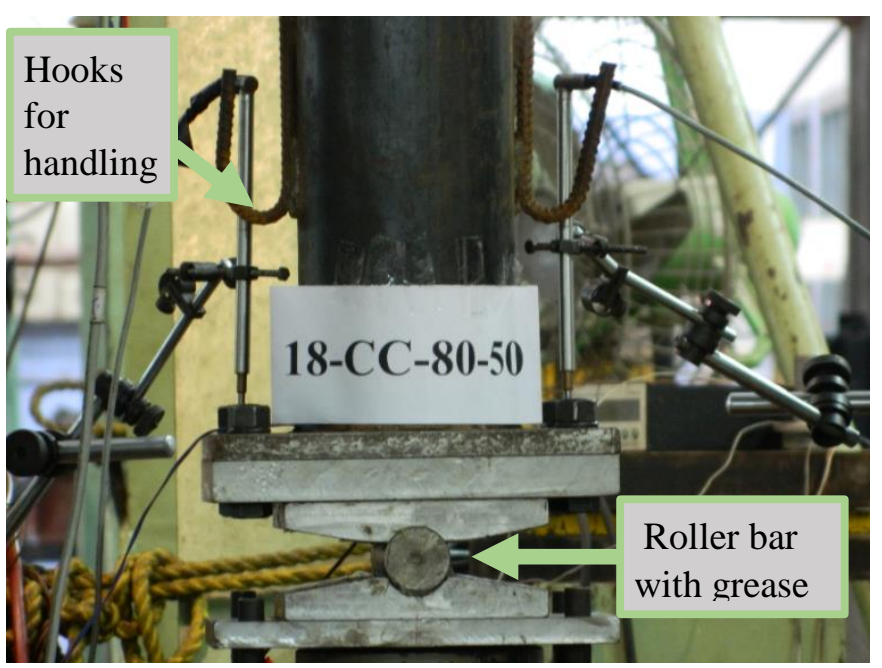

Fig 8 Arrangement of pinned boundary condition 

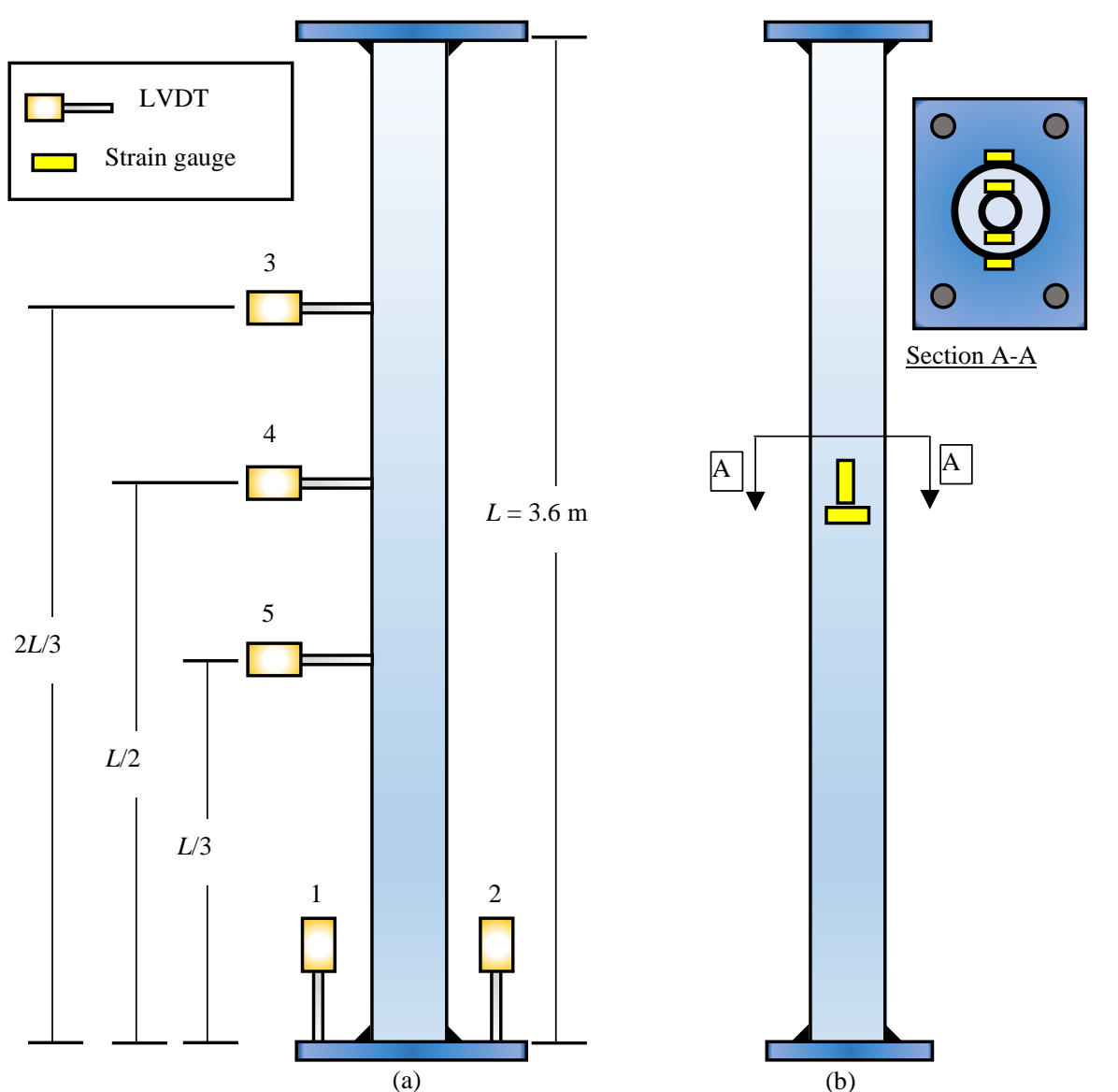

Fig 9 Location of LVDTs and strain gauges. (a) Elevation (b) Side view

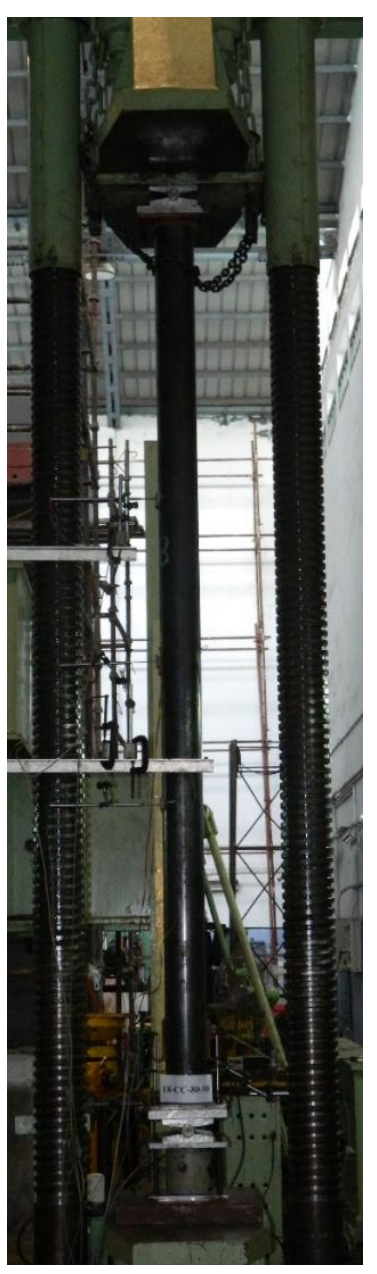

(a)

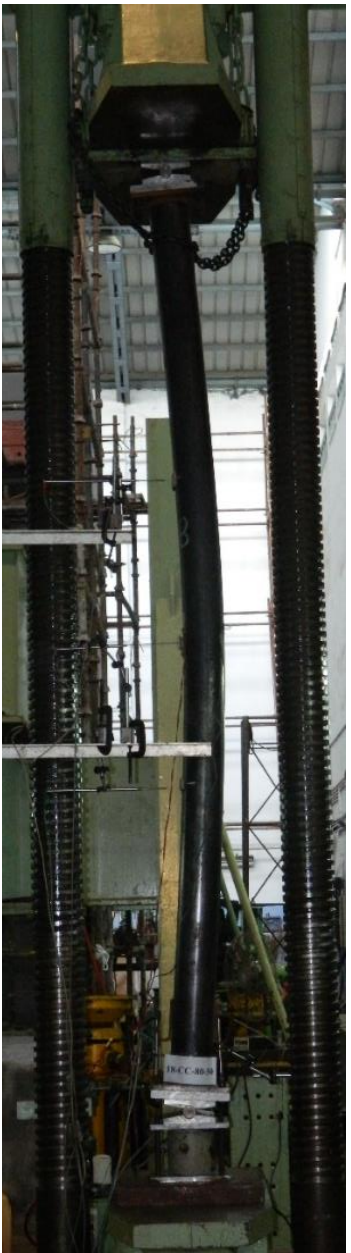

(b)

Fig. 10 Typical failure mode in the test specimen. (a) Initial configuration (b) Deformed configuration 


\section{Test results and discussions}

\subsection{Axial compressive strength}

The maximum axial compressive strength of the test specimens found from the experiment $\left(P_{\text {test }}\right)$ is shown in Table 3. It is lesser than their corresponding superposed strength $\left(P_{\text {sum }}\right)$ due to instability in the member at failure. The stability reduction factor that are specified for CFST design as per EN 1994-1-1 (2004) and ANSI/AISC 360(16) is modified for CSDST cross- sections in Eqs. $(3-7)$ and Eqs. $(8-10)$, respectively. In Table 3 , the instability effect from the test $\left(\chi_{\text {test }}\right)$ is compared with code-based predictions, namely $\chi_{E C 4}$ and $\chi_{A I S C-360}$. The actual instability in the test is lesser than the code predictions. Consequentially, the test axial capacities are higher than codebased capacity predictions as shown in Table 3. This comparison is also presented in Figure 11, along with the literature test data for CSDST [4], [8], [16]. The present experimental data extends the available test database for CSDST in the higher slenderness range, which is useful in the study of column instability.

Table 3

Test axial strength compared with AISC-360(16) and EC4 capacity predictions

\begin{tabular}{|c|c|c|c|c|c|c|c|c|c|}
\hline Sp. ID & $\begin{array}{l}P_{\text {test }} \\
(\mathrm{kN})\end{array}$ & $\begin{array}{l}P_{\text {sum }} \\
(\mathrm{kN})\end{array}$ & $\begin{array}{l}P_{E C 4} \\
(\mathrm{kN})\end{array}$ & $\begin{array}{l}P_{\text {AISC }} \\
(\mathrm{kN})\end{array}$ & $P_{E C 4} / P_{t e s t}$ & $P_{A I S C} / P_{t e s t}$ & $\chi_{\text {test }}$ & $\chi_{E C 4}$ & $\chi_{A I S C}$ \\
\hline S- $-0-40$ & 1801 & 2183 & 1494 & 1420 & 0.83 & 0.79 & 0.83 & 0.68 & 0.69 \\
\hline SS-20-40 & 1694 & 2263 & 1540 & 1470 & 0.91 & 0.87 & 0.75 & 0.68 & 0.68 \\
\hline SS-50-40 & 1750 & 2463 & 1635 & 1582 & 0.93 & 0.90 & 0.71 & 0.98 & 0.67 \\
\hline SS-70-40 & 1568 & 2291 & 1594 & 1546 & 1.02 & 0.99 & 0.68 & 0.69 & 0.70 \\
\hline SS-20-80 & 1901 & 2811 & 1733 & 1675 & 0.91 & 0.88 & 0.68 & 0.62 & 0.64 \\
\hline SS-50-80 & 1998 & 2754 & 1739 & 1689 & 0.87 & 0.85 & 0.73 & 0.63 & 0.65 \\
\hline SS-70-80 & 1959 & 2596 & 1726 & 1670 & 0.88 & 0.85 & 0.75 & 0.66 & 0.67 \\
\hline C- $0-40$ & 1726 & 2259 & 1292 & 1305 & 0.75 & 0.76 & 0.76 & 0.57 & 0.60 \\
\hline CC-20-40 & 1557 & 2424 & 1335 & 1360 & 0.86 & 0.87 & 0.64 & 0.55 & 0.58 \\
\hline CC-50-40 & 1771 & 2392 & 1326 & 1351 & 0.75 & 0.76 & 0.74 & 0.55 & 0.58 \\
\hline CC-70-40 & 1803 & 2684 & 1491 & 1522 & 0.83 & 0.84 & 0.67 & 0.56 & 0.58 \\
\hline CC-20-80 & 1496 & 2813 & 1422 & 1467 & 0.95 & 0.98 & 0.53 & 0.51 & 0.55 \\
\hline CC- $50-80$ & 1705 & 2781 & 1438 & 1481 & 0.84 & 0.87 & 0.61 & 0.52 & 0.55 \\
\hline CC-70-80 & 1899 & 2900 & 1574 & 1612 & 0.83 & 0.85 & 0.65 & 0.54 & 0.57 \\
\hline
\end{tabular}

$P_{u}=\chi P_{\text {sum }}$

$P_{s u m}=A_{s o} f_{y o}+A_{s i} f_{y i}+A_{c}\left(0.8 f_{c m}\right)$

3.1.1. EN 1994-1-1 (2004) based instability factor

$\chi_{E C 4}=\frac{1}{\phi+\sqrt{\phi^{2}-\lambda^{2}}}$

where, $\phi=0.5\left[1+\alpha(\lambda-0.2)+\lambda^{2}\right]$

$$
\lambda_{E C 4}=\sqrt{\frac{P_{\text {sum }}}{P_{c r, E C 4}}}
$$

$P_{c r, E C 4}=\frac{\pi^{2} E I_{e f f, E C 4}}{L_{e f f}^{2}}$

$$
E I_{e f f, E C 4}=E_{s o} I_{s o}+E_{s i} I_{s i}+0.6 E_{c} I_{c}
$$

$$
\lambda_{\text {AISC }}=\sqrt{\frac{P_{\text {sum }}}{P_{c r, A I S C}}}
$$

$$
P_{c r, A I S C}=\frac{\pi^{2} E I_{e f f, A I S C}}{L_{e f f}^{2}}
$$

$E I_{e f f, A I S C}=E_{s o} I_{s o}+E_{s i} I_{s i}+C_{3} E_{c} I_{c}$

$$
C_{3}=0.45+3\left(\frac{A_{s o}+A_{s i}}{A_{g}}\right) \leq 0.9
$$

$$
\chi_{\text {test }}=\frac{P_{\text {test }}}{P_{\text {sum }}}
$$




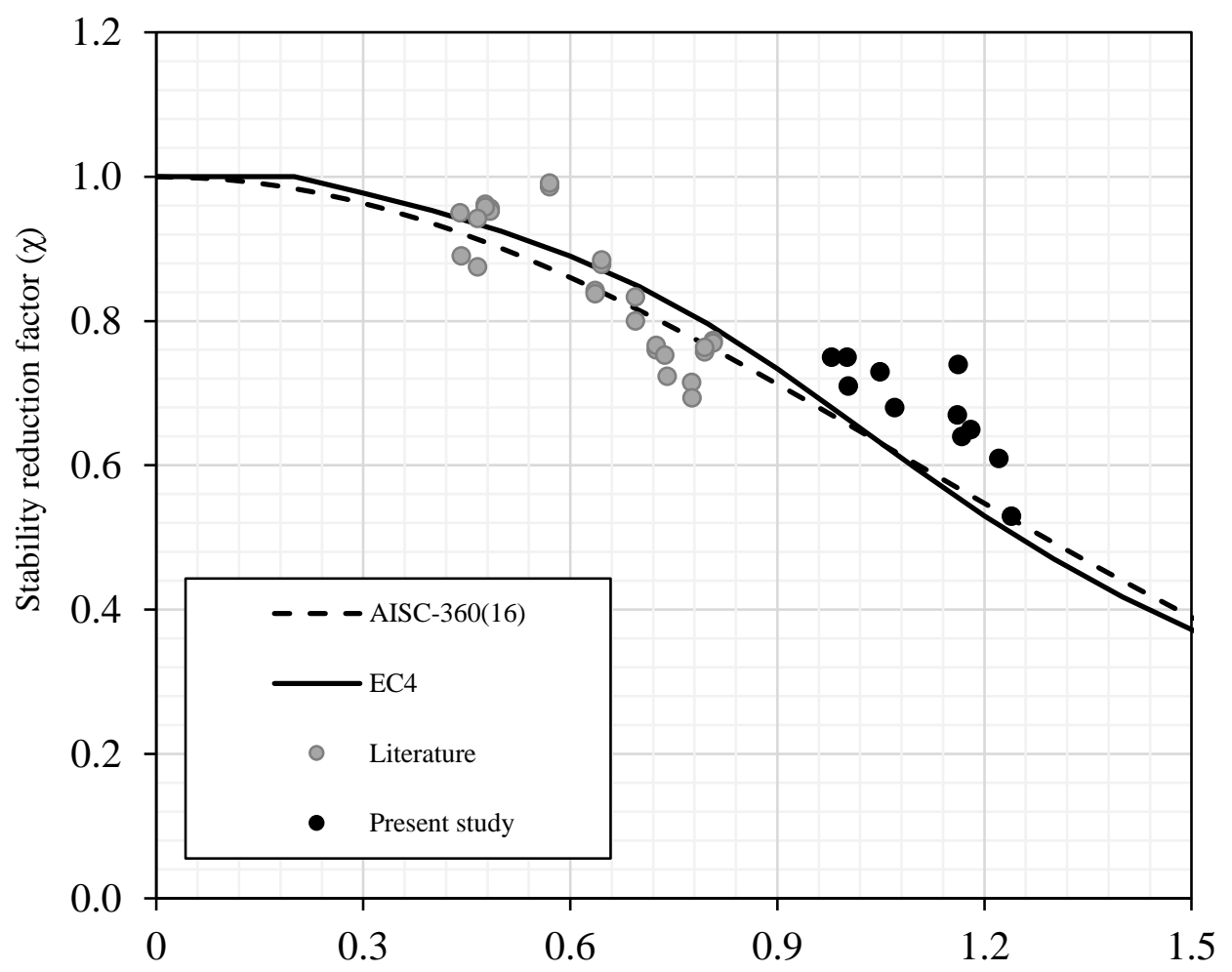

Non-dimentional slenderness ratio $(\lambda)$

Fig. 11 Comparison of test capacities and code predictions

Over-strength is observed in the test axial capacity $\left(P_{\text {test }}\right)$ of the specimens when compared to code based equations. Square specimens have an average over-strength of $12 \%$ except SS-70-40 that had concreting issues. Circular specimens have an average over strength of $25 \%$ for normal strength, and $15 \%$ for high strength concrete. Over-strength in the buckling capacity of CFST has also been observed in few other test data reported in literature, like Han [21], Perea [22] and Xiong et al. [23]. Han [21] has regarded the axial capacity prediction by code recommendations as conservative, and thereby higher reliability is marked for these predictions An et al. [24]. Perea et al. [22], [25] and Xiong et al. [23] have reported frictional resistance at the supports as the reason for over-strength in test capacities, and corrections are made in the raw data. Perceiving these reports, the friction resistance at the supports are minimized in the present experiment by applying grease in the roller bar. In spite of it, the over-strength is found in the tests. The magnitude of initial imperfection in the test specimens is $L / 7000$, and it is very low compared to the initial imperfections $(L / 1000$ or $L / 1500)$ assumed in the development of code equations [1], [2]. This disparity makes the code-based capacity predictions significantly conservative. The magnitude and shape of the initial imperfection profile is crucial in undertanding the long column behaviour of concrete filled steel tubes, unlike slender hollow steel tubes whose failure load is always less than the critical buckling load Galambos and Surovek [18]. The associated concrete confinement effect is one of the factors for the increase in the axial capacity of test specimens. This effect is discussed in following sections using the axial and circumferential strains measured during the test.

\subsection{Experimental behaviour curves}

\subsubsection{Axial compressive load-axial deformation curves}

A typical axial load versus axial shortening curve of the test specimens is shown in Figure 12. The axial deformations measured from LVDT-1 and LVDT-2 are the same untill the specimen undergoes buckling. At the ultimate point, the plots diverge due to rotation of the end plate. The compression side shows larger shortening and the tension side shows unloading. The actual axial shortening in the specimen is the average of these two values, which has negligible rate of increase beyond the ultimate load. Even though, the compression testing machine is load-controlled, few points beyond ultimate is recorded through manual operation as mentioned before. This is the reason why the axial deformation in the specimen remains constant beyond ultimate load point. Axial shortening $(\Delta)$ of the test specimens at the ultimate load point is reported in Table 4.

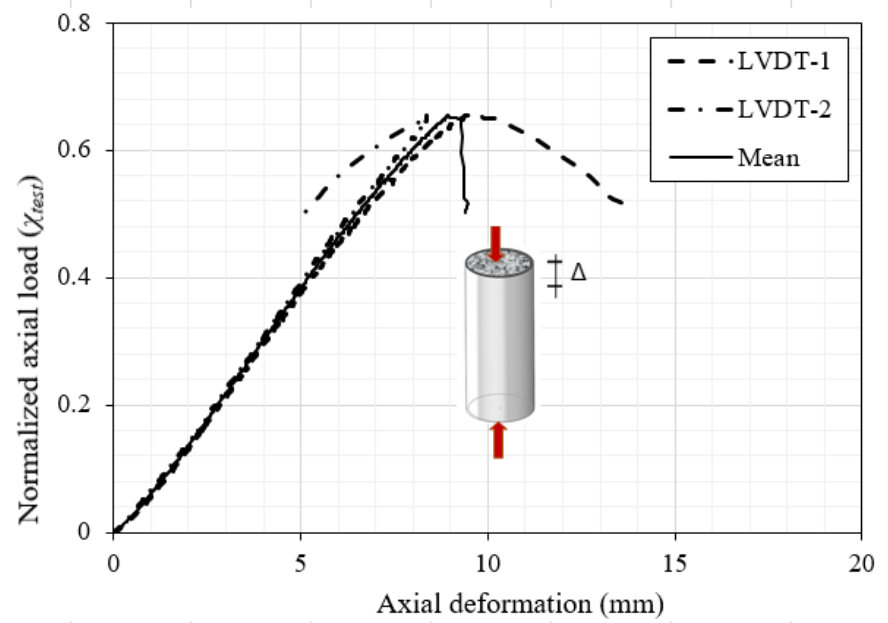

Fig 12 Typical axial deformation behaviour of test specimens

\subsubsection{Axial compressive load-lateral deflection curves}

The axial load versus lateral displacements measured at the mid-height of the specimens is presented in Figures $13(\mathrm{a}-\mathrm{b})$. The axial loading (y-axis) is normalized with respect to the corresponding cross-section strength $\left(P_{\text {sum }}\right)$ of the specimens. Since the concrete strength in these specimens are not exactly the same, absolute load plot does not make a meaningful comparison, so therefore, the values are normalized. The normalized axial load in the plots is in fact the stability reduction factor from the tests $\left(\chi_{\text {test }}\right)$. This factor is higher compared to the corresponding code provisions $\left(\chi_{\text {AISC-360 }}, \chi_{E C 4}\right)$ (Table 3$)$, indicating over-strength in the test results. The $\chi_{\text {test }}$ value for high strength concrete is lesser compared to normal strength concrete in both square and circular specimens. It is obvious as the instability of the specimen increases with high strength concrete filling, and this effect could be captured in the present strength equations used for long column design [1], [2]. Hollowness ratio is a major parameter that has significant effect in the buckling of CSDST, especially in circular cross-section. The $\chi_{\text {test }}$ value in CSDST is lesser compared to CFST both in square as well as circular cross-sections. Further, 
the instability is observed to be the least for CSDST specimens with $20 \%$ hollowness. The reasons for higher instability in CSDST are inferred as, (i) increase in the non-dimensional slenderness ratio $(\lambda)$, (ii) increase in the unavoidable initial imperfections compared to an equivalent CFST (due to practical difficulties in developing perfect concentricity between the inner and outer steel tubes). (iii) The inner steel tube is located in low stress zone of the cross-section and therefore it is contributing less in buckling resistance. Therefore, eventhough the present design methods [1], [2] have predicted the axial capacity of test specimens conservatively, their effective flexural rigidity has to be studied to understand the significance of inner steel tube in global buckling resistance.

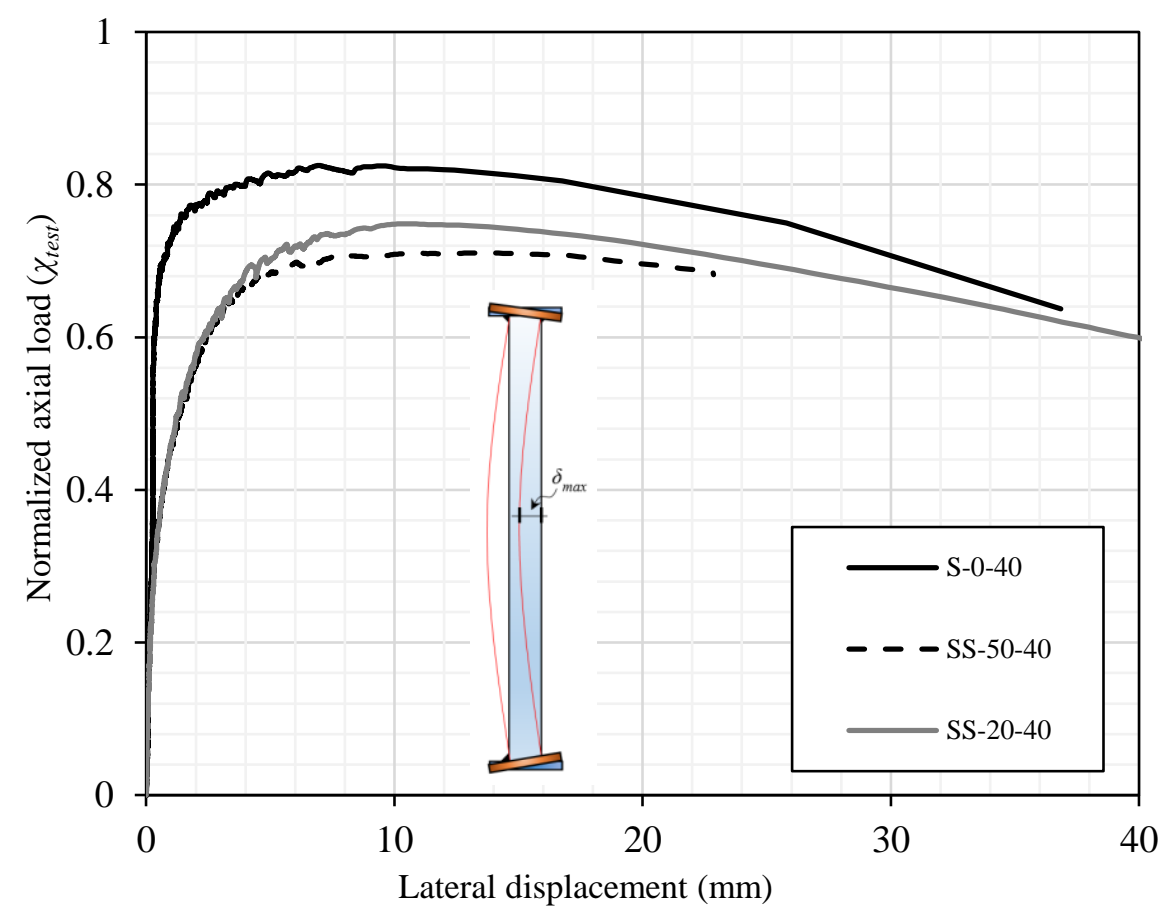

(a) Square specimens with normal strength concrete

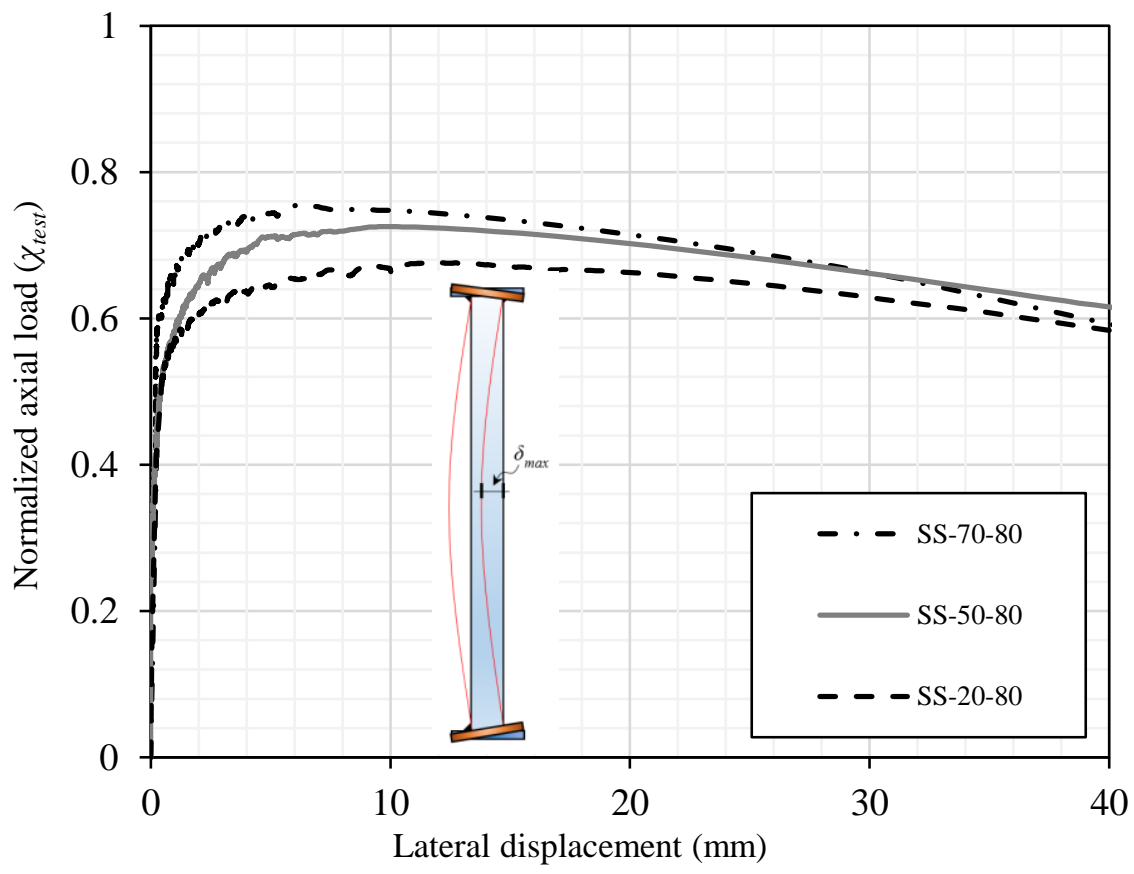

(b) Square specimens with high strength concrete 


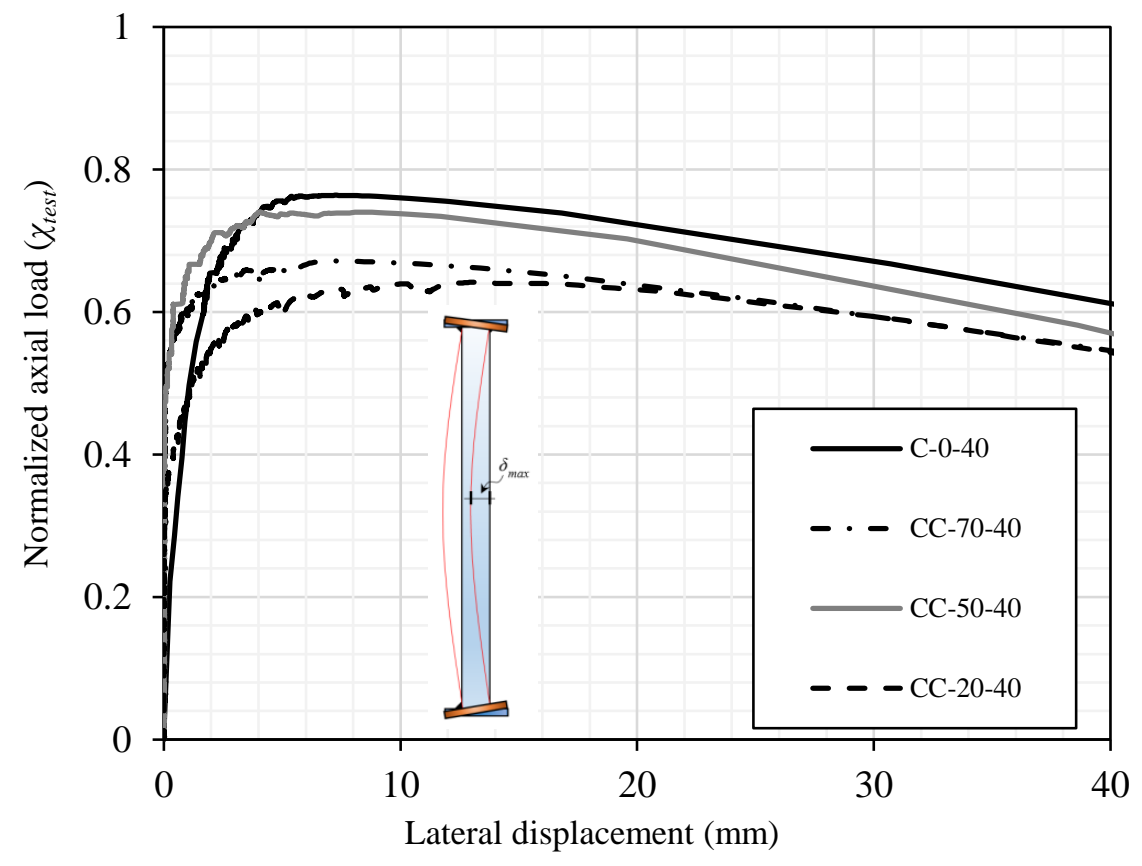

(c) Circular specimens with normal strength concrete

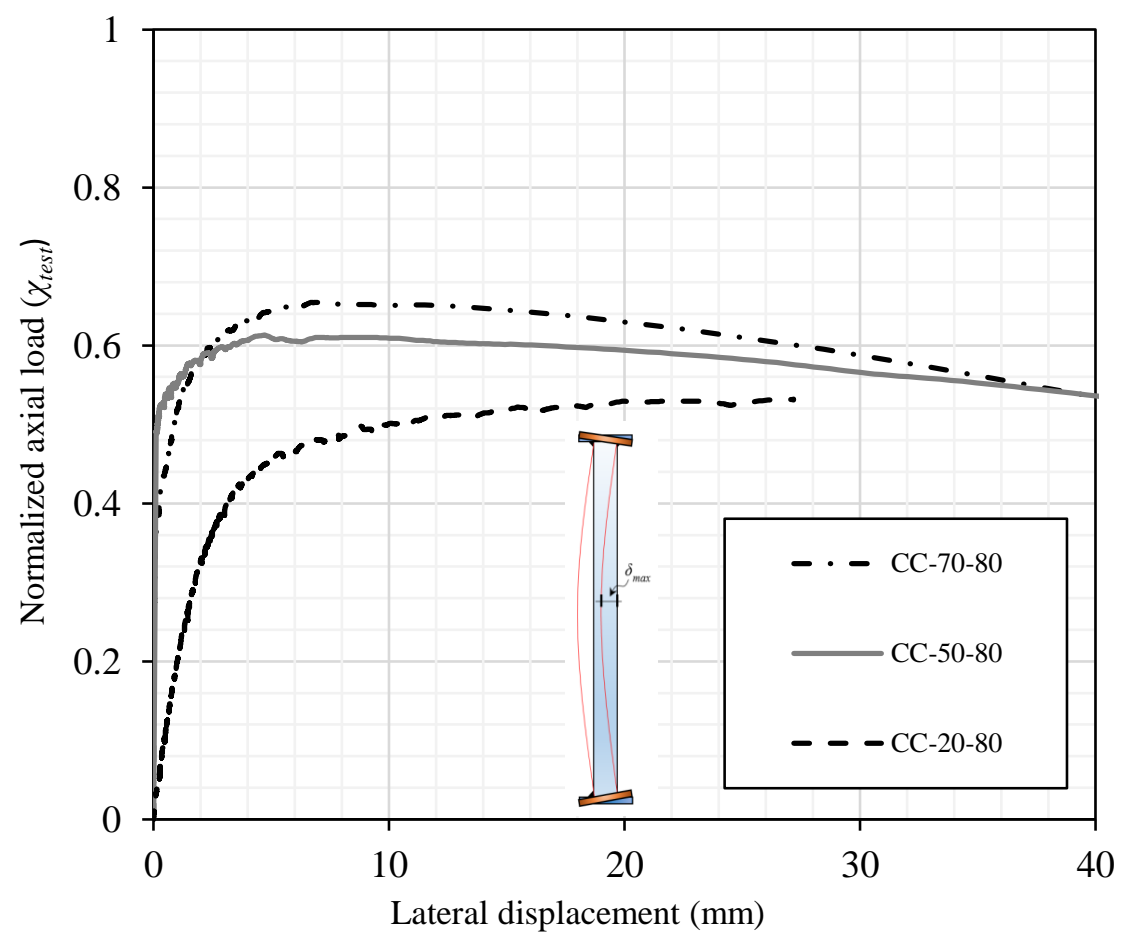

(d) Circular specimens with high strength concrete

Fig.13 Axial compressive loading versus mid-height lateral deflection

\subsubsection{Axial compressive load - axial and circumferential strain curves}

The plots of axial load versus longitudinal (l) and circumferential (c) strains in the test specimens is presented in Figures $14(\mathrm{a}-\mathrm{d})$. The behaviour of the test specimens is linear upto $80 \%$ of the peak load. Development of nonlinearlity in the behaviour is found for longitudinal strain values beyond the non-proportional limit of steel material. The maximum strain in the specimens at the ultimate load point is greater than $2000 \mu$ (Table 4), whereas, the maximum strain at proportional limit in the material characterization of steel is found to be around $1700 \mu$. This indicates an inelastic buckling failure, and it is the expected mode of failure for steel columns with non-dimensional slenderness $(\lambda)$ between 0.3 and 1.4 [18]. The load drops suddenly after reaching the peak load and it indicates the buckling mode of failure in the test specimens. The longitudinal $\left(\varepsilon_{o, h}\right)$ and circumferential strains $\left(\varepsilon_{o, l}\right)$ measured from the most compressed fiber of the specimen at the ultimate load is reported in Table 4. The longitudinal strains measured in the inner steel tubes is also shown in Table 4 . The $\varepsilon_{i, l o n g}$ values are lesser than their corresponding outer steel tubes, which confirms the composite action within the cross-section, and simultaneous buckling failure of the inner and outer steel tubes. The ratio of hoop strain to longitudinal strain in the outer steel tube $\left(v_{o}\right)$ at the ultimate load (Table 4) is consistently higher than the average Poisson's ratio of 0.28 measured in the tension coupon test. A substantial lateral pressure due to interaction between the infilled concrete and the outer steel tubes (i.e. concrete confinement) is considered as the reason for increased strain ratios, which has incurred over-strength in the test specimens. This signifies the effect of column initial imperfections on the buckling capacity of concrete filled steel tubes, and the presence of concrete confinement in slender columns with very low initial imperfections. 


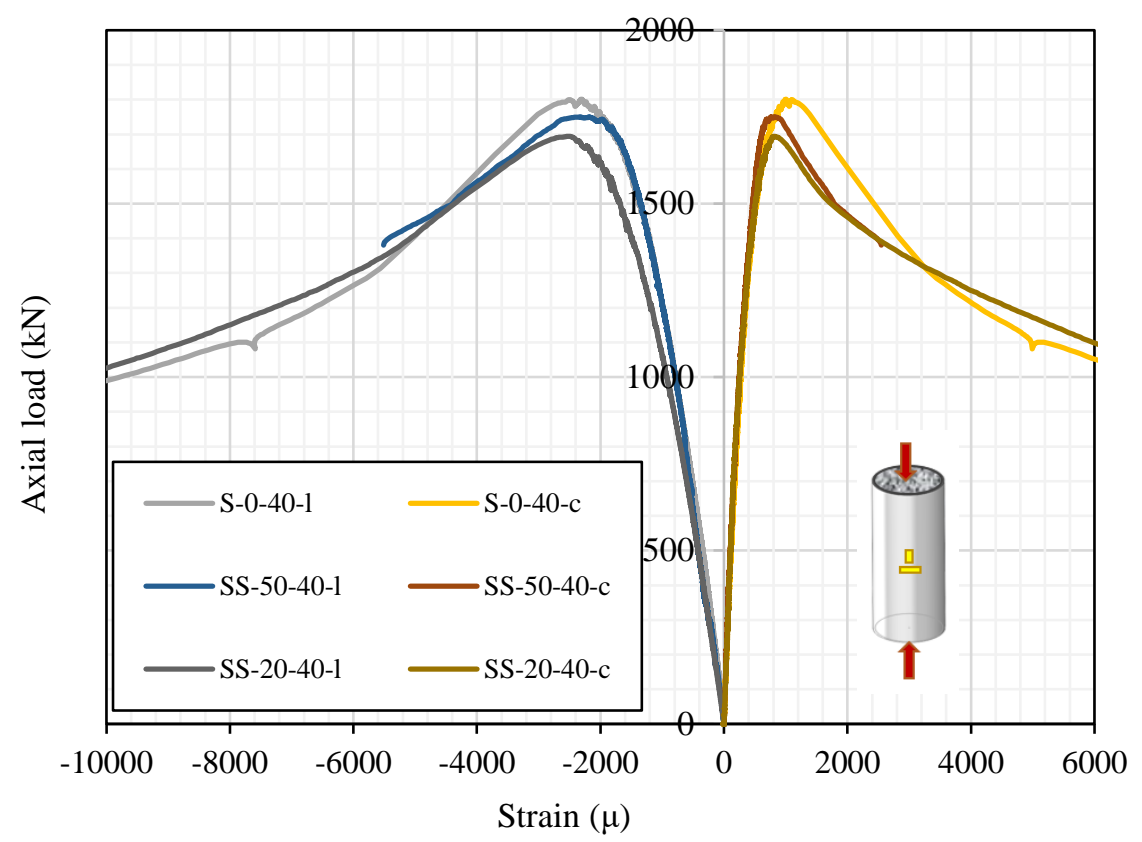

(a) Square specimens with normal strength concrete

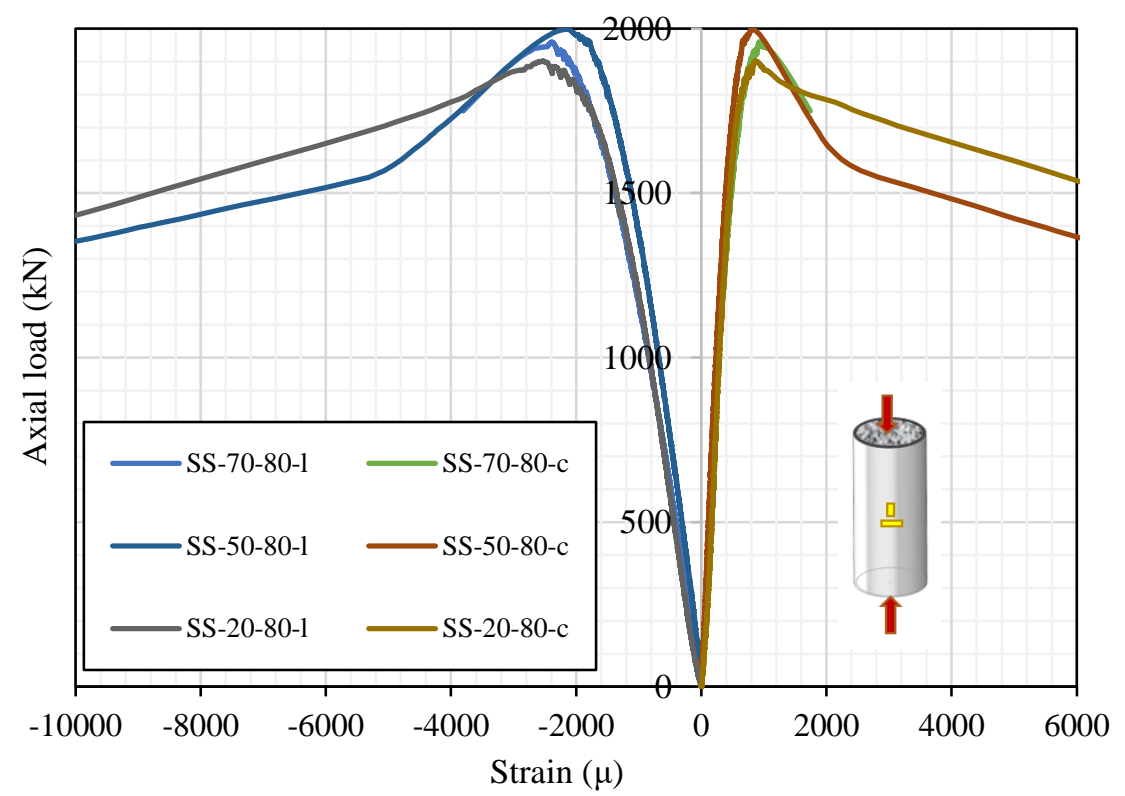

(b) Square specimens with high strength concrete

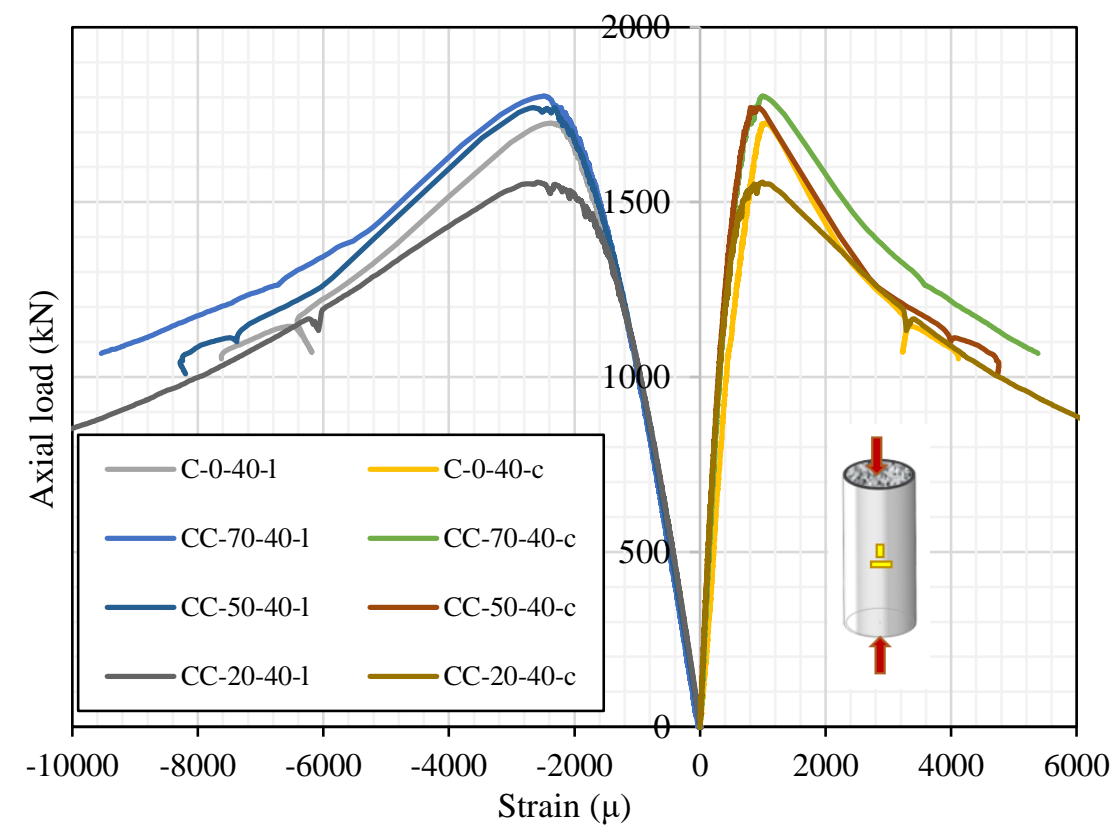

(c) Circular specimens with normal strength concrete 


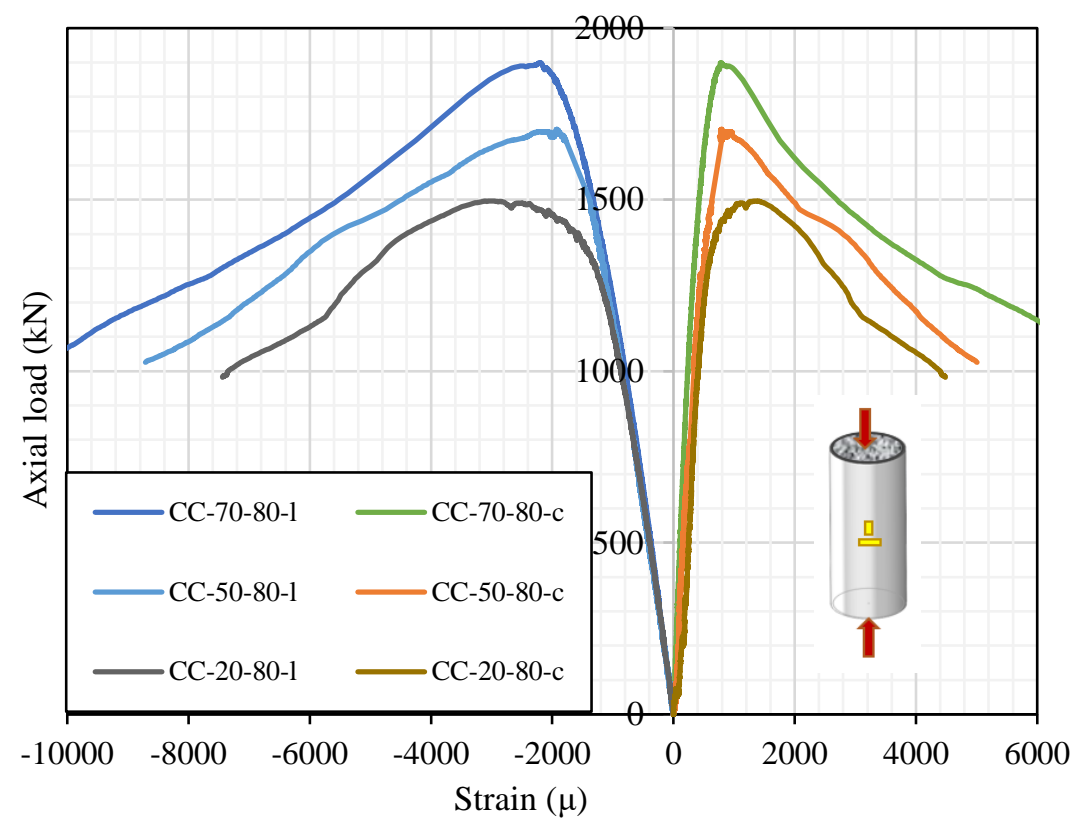

(d) Circular specimens with high strength concrete

Fig. 14 Axial load versus strain curves

Table 4

Maximum strain, axial shortening and lateral deflection at the ultimate load

\begin{tabular}{|c|c|c|c|c|c|c|c|}
\hline Sp. ID & $\begin{array}{l}P_{\text {test }} \\
(\mathrm{kN})\end{array}$ & $\begin{array}{c}\varepsilon_{o, l o n g} \\
(\mu)\end{array}$ & $\begin{array}{c}\varepsilon_{i, l \text { long }} \\
(\mu)\end{array}$ & $\begin{array}{c}\varepsilon_{o, \text { circum }} \\
\quad(\mu)\end{array}$ & $v_{o}$ & $\begin{array}{c}\Delta_{a x} \\
(\mathrm{~mm})\end{array}$ & $\begin{array}{c}\delta_{\text {lat }} \\
(\mathrm{mm})\end{array}$ \\
\hline S-0-40 & 1801 & 2315 & NA & 1003 & 0.4 & 9.2 & 7.0 \\
\hline SS-20-40 & 1694 & 2506 & 1768 & 807 & 0.32 & 7.22 & 10.36 \\
\hline SS-50-40 & 1750 & 2189 & 1821 & 764 & 0.35 & 8.00 & 11.01 \\
\hline SS-70-40 & 1568 & 2261 & 2164 & 855 & 0.38 & 6.47 & 12.05 \\
\hline SS-20-80 & 1901 & 2522 & 2049 & 867 & 0.34 & 8.65 & 11.87 \\
\hline SS-50-80 & 1998 & 2161 & 1881 & 818 & 0.38 & 8.51 & 10.59 \\
\hline SS-70-80 & 1959 & 2379 & 2372 & 925 & 0.39 & 8.79 & 6.09 \\
\hline C- $-0-40$ & 1726 & 2370 & - & 1044 & 0.44 & 9.15 & 7.54 \\
\hline CC-20-40 & 1557 & 2590 & 1337 & 994 & 0.38 & 7.10 & 13.44 \\
\hline CC-50-40 & 1771 & 2244 & 2046 & 805 & 0.36 & 9.43 & 4.59 \\
\hline CC-70-40 & 1803 & 2490 & 2330 & 1003 & 0.40 & 8.72 & 7.46 \\
\hline CC-20-80 & 1496 & 3008 & - & 1351 & 0.4 & 7.1 & 27.2 \\
\hline CC-50-80 & 1705 & 1932 & 1795 & 787 & 0.41 & 7.47 & 4.71 \\
\hline CC-70-80 & 1899 & 2211 & 1899 & 788 & 0.36 & 8.92 & 7.18 \\
\hline
\end{tabular}

\subsection{Effective flexural rigidity $\left(E I_{\text {eff }}\right)$}

The effective flexural rigidity of the test specimens is derived from the experimental results using Euler-Bernoulli beam theory. This theory is applicable till the ultimate load point, where $\delta_{\text {lat }}<0.01 L$ (i.e. small deflection,), beyond which the lateral deflections are large. The bending moment at the mid-height of the specimen due to lateral deflection $(M=P \delta)$ and the curvature developed $(\varphi)$ is plotted to find $E I_{\text {eff. }}$ A representative plot (for circular specimens with normal strength concrete) is presented in Figure 15. In the previous section, the suitability of adopting the existing design principles specified for CFST long columns [1], [2] to CSDST is checked by comparing the axial capacities from the test. The predictions are found to be conservative for the selected cross-sections. However, the degree of conservativeness is lesser for specimens with low hollowness ratio. This phenomenon is further clarified by comparing the effective flexural rigidity of the specimens from test and code-based predictions, as shown in Table 5. The $E I_{\text {eff }}$ from the tests is lesser compared to the code equations since the specimens have failed by inelastic buckling, and reduced stiffness modulus is obtained from the $M-\varphi$ plots. The mean and standard deviation of $E I_{\text {eff }}$ ratio using EC4 is 0.77 and 0.1 , whereas, AISC-360 gives 0.69 and 0.08 for square crosssection. In circular specimens, the mean and standard deviation of $E I_{\text {eff }}$ ratio is 0.93 and 0.1 using EC4, and AISC-360 gives 0.81 and 0.09 . This level of accuracy in $E I_{\text {eff }}$ prediction is considered to be acceptable as per design standards [25]. However, the $E I_{\text {eff }}$ of CSDST with $20 \%$ hollowness is consistently below average, and therefore, the reliability of code-based design equations will be less for CSDST with low hollowness ratio. The normalized $E I_{\text {eff }}$ of CSDST specimens with respect to the values of CFST is given in Table 5. It shows that the flexural rigidity and buckling resistance of CSDST columns with smaller hollowness (less than $50 \%$ ) is relatively low. 


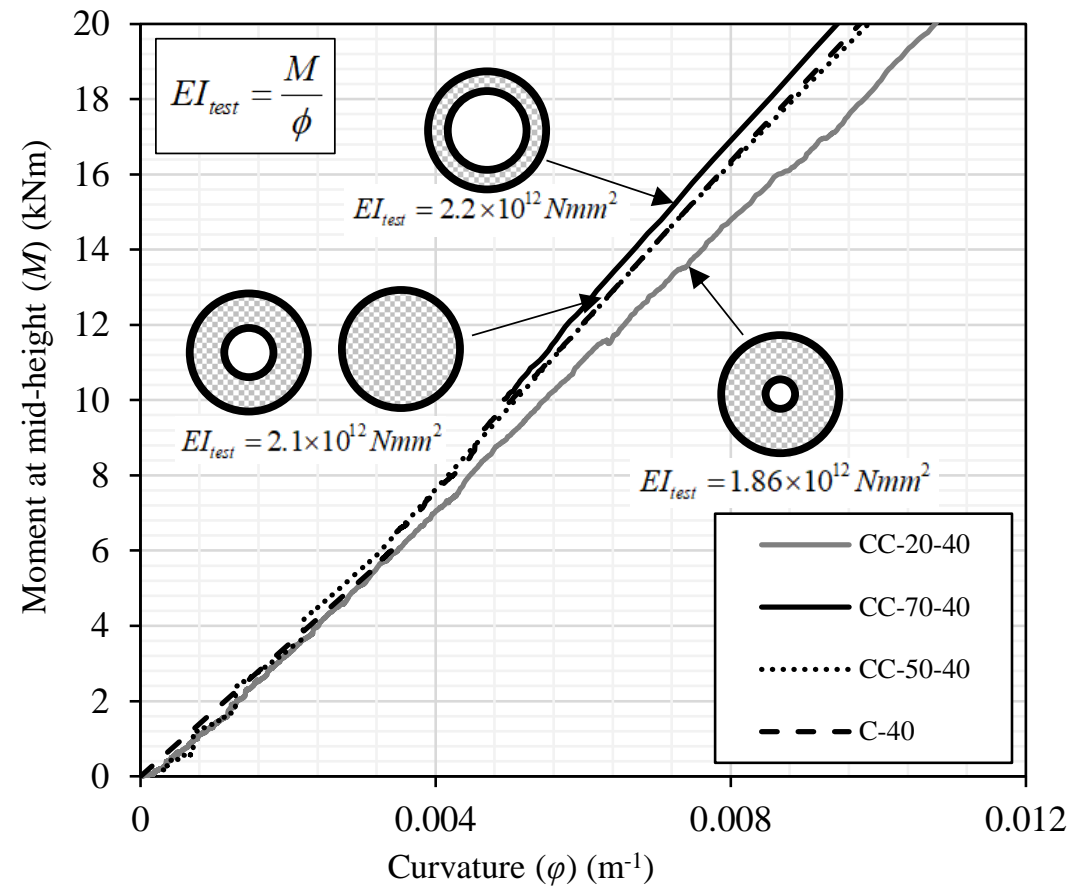

Fig. 15 Moment versus curvature plots

Table 5

Comparison of effective flexural rigidity from test and code equations

\begin{tabular}{|c|c|c|c|c|c|c|}
\hline Sp. ID & $\begin{array}{c}E I_{\text {test }} \\
\left(10^{12} \mathrm{~N} \mathrm{~mm}^{2}\right)\end{array}$ & $\begin{array}{c}E I_{E C 4} \\
\left(10^{12} \mathrm{~N} \mathrm{~mm}^{2}\right)\end{array}$ & $\begin{array}{c}E I_{\text {AISC }} \\
\left(10^{12} \mathrm{~N} \mathrm{~mm}^{2}\right)\end{array}$ & $E I_{\text {tes }} / E I_{E C 4}$ & $E I_{\text {tes }} / E I_{\text {AISC }}$ & $\begin{array}{c}\text { Normalized } \\
\text { EI }_{\text {test }}\end{array}$ \\
\hline S-0-40 & 2.22 & 3.03 & 3.35 & 0.73 & 0.66 & 1.00 \\
\hline SS-20-40 & 1.90 & 3.10 & 3.43 & 0.61 & 0.55 & 0.86 \\
\hline SS-50-40 & 2.63 & 3.22 & 3.54 & 0.82 & 0.74 & 1.18 \\
\hline SS-70-40 & - & 3.29 & 3.45 & - & - & - \\
\hline SS-20-80 & 2.50 & 3.22 & 3.75 & 0.78 & 0.67 & 0.94 \\
\hline SS-50-80 & 3.00 & 3.29 & 3.75 & 0.91 & 0.80 & 1.13 \\
\hline \multirow[t]{3}{*}{ SS-70-80 } & 2.65 & 3.40 & 3.76 & 0.78 & 0.70 & 1.00 \\
\hline & & & Mean & 0.77 & 0.69 & \\
\hline & & & Std dev & 0.10 & 0.08 & \\
\hline C-0-40 & 2.10 & 2.30 & 2.56 & 0.91 & 0.82 & 1.00 \\
\hline CC-20-40 & 1.86 & 2.34 & 2.66 & 0.80 & 0.70 & 0.89 \\
\hline CC-50-40 & 2.10 & 2.33 & 2.64 & 0.90 & 0.79 & 1.00 \\
\hline CC- $70-40$ & 2.20 & 2.62 & 2.87 & 0.84 & 0.77 & 1.05 \\
\hline CC-20-80 & 2.22 & 2.40 & 2.85 & 0.92 & 0.78 & 0.74 \\
\hline CC-50-80 & 2.50 & 2.45 & 2.89 & 1.02 & 0.86 & 0.83 \\
\hline \multirow[t]{3}{*}{ CC-70-80 } & 3.00 & 2.74 & 3.07 & 1.10 & 0.98 & 1.00 \\
\hline & & & Mean & 0.93 & 0.81 & \\
\hline & & & Std dev & 0.10 & 0.09 & \\
\hline
\end{tabular}

\section{Summary and conclusions}

The global stability of concrete sandwiched double steel tubular columns (CSDST) is investigated by conducting axial compression tests. Twelve CSDST and two CFST long column specimens $(\lambda \approx 1)$ are tested with hollowness ratio as the primary parameter. Shape of steel tubes and concrete strength are secondary parameters for the experimental study. Three types of hollowness are selected for CSDST specimens, namely, 20\%, 50\% and $70 \%$. Square and circular shapes are considered for the outer and inner steel tubes. Normal and high strength concrete of $40 \mathrm{~N} / \mathrm{mm}^{2}$ and $80 \mathrm{~N} / \mathrm{mm}^{2}$ respectively are selected as the in-fill. The behaviour of CSDST specimens are comparatively studied with CFST. The applicability of design equations specified for long column CFST in ANSI/AISC 360(16) and EN 1994-1-1 (2004) to CSDST column design is quantified and reported. The salient conclusions from the study are enumerated as below.

- The buckling capacity of CSDST is found to be lesser than an equivalent CFST long column specimen. The reasons are; (i) nondimensional slenderness ratio $(\lambda)$ of CSDST is higher than CFST for the same $L / D$, (ii) the degree of initial imperfections in CSDST is larger than CFST due to unavoidable error in the concentricity of inner and outer steel tubes, and (iii) the contribution of flexural rigidity provided by the inner steel tube is lesser than the theoretical predictions.

- The global instability of CSDST columns is inversely related to the hollowness ratio of the cross-section. This phenomenon is observed in both square as well as circular cross-sections irrespective of the sandwiched concrete strength.

- The test axial capacity of the specimens is greater than the ANSI/AISC 360(16) and EN 1994-1-1 (2004) based strength predictions. The average degree of conservativeness in the code predictions is $12 \%$ and $20 \%$ for square and circular specimens, respectively. Low initial imperfection in the steel tubes and concrete confinement have increased the test specimen capacity.

- Effective flexural rigidity $\left(E I_{\text {eff }}\right)$ derived from the experimental results is in good agreement with the code-based predictions except for CSDST with $20 \%$ hollowness. It enunciates the inverse relation of column instability and hollowness ratio in CSDST.

- The long column axial capacity equations for CFST in ANSI/AISC 360(16) and EN 1994-1-1 (2004) can be adopted for CSDST However, the equations are less conservative for cross-sections with less than $50 \%$ hollowness. 


\section{Appendix-I}

The concrete mix proportion is prepared with reference to the Indian Standards IS:456-2000 and IS:10262-2009. The quantities of concrete ingredients used for preparing the normal $\left(40 \mathrm{~N} / \mathrm{mm}^{2}\right)$ and high strength concrete $\left(80 \mathrm{~N} / \mathrm{mm}^{2}\right)$ are given in Tables A.I-1 and A.I-2, respectively.

Table A.I.1

Quantity of ingredients in normal strength concrete $\left(40 \mathrm{~N} / \mathrm{mm}^{2}\right)$

\begin{tabular}{lc}
\hline \multicolumn{1}{c}{ Raw materials } & Quantity $\left(\mathrm{kg} / \mathrm{m}^{3}\right)$ \\
\hline Water & 180 \\
Cement (OPC53) & 400 \\
Flyash & 100 \\
Coarse aggregate $(12.5 \mathrm{~mm} / 6 \mathrm{~mm})$ & 836 \\
Sand (M) & 896 \\
Chemical admixture (BASF ACE 30 IT) & 3 \\
\hline
\end{tabular}

\section{Table A.I.2}

Quantity of ingredients in high strength concrete $\left(80 \mathrm{~N} / \mathrm{mm}^{2}\right)$

\begin{tabular}{lc}
\hline \multicolumn{1}{c}{ Raw materials } & Quantity $\left(\mathrm{kg} / \mathrm{m}^{3}\right)$ \\
\hline Water & 185 \\
Cement (OPC53) & 550 \\
Flyash & 200 \\
Micro-silica & 50 \\
Coarse aggregate $(12.5 \mathrm{~mm} / 6 \mathrm{~mm})$ & 727 \\
Sand (M) & 691 \\
Chemical admixture (BASF ACE 30 IT) & 5.25 \\
\hline
\end{tabular}

\section{Acknowledgements}

The authors wish to extend their thanks to TATAstructura for supplying the steel tubes for this experimental work. They are also very thankful for the lab staff at Structural engineering lab, IIT Madras for their help during the experimental process.

\section{References}

[1] EN 1994-1-1, "Eurocode 4: Design of composite steel and concrete structures Part 1-1: General rules and rules for buildings," 2004.

[2] ANSI/AISC, "Specification for Structural Steel Buildings," 2016.

[3] P. Hsiao, K. K. Hayashi, R. Nishi, X. Lin, and M. Nakashima, "Investigation of ConcreteFilled Double-Skin Steel Tubular Columns with Ultrahigh-Strength Steel," Journal of Structural Engineering, ASCE, 2014, pp. 1-8.

[4] M. L. Romero, A. Espinos, J. M. Portolés, A. Hospitaler, and C. Ibañez, "Slender doubletube ultra-high strength concrete-filled tubular columns under ambient temperature and fire," Engineering Structures, 2015, vol. 99, pp. 536-545.

[5] H. Lu, X.-L. Zhao, and L.-H. Han, "FE modelling and fire resistance design of concrete filled double skin tubular columns," Journal of Constructional Steel Research, 2011, vol. 67, no. 11, pp. 1733-1748.

[6] F. Zhang, C. Wu, X. Zhao, Z. Li, A. Heidarpour, and H. Wang, "Numerical Modeling of Concrete-Filled Double-Skin Steel Square Tubular Columns under Blast Loading," Journal of performance of constructed facilities (ASCE), 2015, vol. 29, no. 5, pp. 1-12.

[7] C. B. Ritchie, J. A. Packer, M. V Seica, and X. Zhao, "Behaviour and analysis of concretefilled rectangular hollow sections subject to blast loading," Journal of Constructional Steel Research, 2018, vol. 147, pp. 340-359.

[8] Z. Tao, L.-H. Han, and X.-L. Zhao, "Behaviour of concrete-filled double skin (CHS inner and CHS outer) steel tubular stub columns and beam-columns," Journal of Constructional Steel Research, 2004, vol. 60, no. 8, pp. 1129-1158.

[9] K. Uenaka, H. Kitoh, and K. Sonoda, "Concrete filled double skin circular stub columns under compression," Thin-Walled Structures, 2010, vol. 48, no. 1, pp. 19-24.

[10] X.-L. Zhao and R. Grzebieta, "Strength and ductility of concrete filled double skin (SHS inner and SHS outer) tubes," Thin-Walled Structures, 2002, vol. 40, no. 2, pp. 199-213.

[11] L.-H. Han, Z. Tao, H. Huang, and X.-L. Zhao, "Concrete-filled double skin (SHS outer and CHS inner) steel tubular beam-columns," Thin-Walled Structures, 2004, vol. 42, no. 9, pp. 1329-1355.

\section{NOTATIONS}

$A_{c}, A_{s o}, A_{s i}, A_{g}$ - Area of concrete, outer steel tube, inner steel tube, and gross cross-section, respectively

$B$ - Width of general tubular cross-section

$D, D_{o}, D_{i}$ - Diameter or width of general steel tube, outer steel tube, and inner steel tube, respectively

$E_{c}, E_{s}, E_{s o}, E_{s i}$ - Young's modulus of concrete, general steel, outer steel tube, and inner steel tube, respectively

$I_{c}, I_{s}, I_{s o}, I_{s i}-$ Moment of inertia of concrete, general steel, outer steel tube, and inner steel tube, respectively

$L, L_{e f f}$ - Length of the test specimen and effective length, respectively

$P_{c r, E C 4}-$ Elastic $c$ ritical buckling load as per EC4

$P_{c r, A I S C}$ - Elastic $c$ ritical buckling load as per AISC-360(16)

$P_{E C 4}-$ Axial capacity predicted using EC4 provisions

$P_{\text {AISC }}$ - Axial capacity predicted using AISC-360(16) provisions

$P_{\text {sum }}$ - Superimposed axial strength of steel and concrete $\left(P_{\text {sum }}=A_{s e} f_{y o}+A_{s i} f_{y i}+\right.$ $\left.0.8 A_{c} f_{c m}\right)$

$P_{\text {test }}$ - Ultimate strength of the specimens from test

$P_{u}$ - Ultimate axial capacity

$f_{c c}$ - Confined compressive strength of concrete

$f_{c m}$ - Mean compressive strength of concrete cube

$f_{y}, f_{y o}, f_{y i}-$ Yield strength of general steel, outer and inner steel tubes, respectively

$f_{u o}, f_{u i}$ - Ultimate strength of outer and inner steel tubes, respectively

$h_{r}$ - Hollowness ratio $\left(h_{r}=D_{i} /\left(D_{o}-2 t_{o}\right)\right)$

$k$-Factor to account for concrete strength enhancement due to lateral confinement

$r_{o}, r_{i}$ - Outer and Inner radius of sandwiched concrete

$t, t_{o}, t_{i}$ - Thickness of a general steel tube, outer steel tube and inner steel tube, respectively

$\gamma-$ Initial eccentricity factor

$\Delta-$ Axial deformation

$\delta_{c}$ - Imperfection due to curvature effect

$\delta_{\max }$ - Maximum lateral displacement

$\delta_{o}$ - Initial lateral displacement

$\varepsilon_{c}, \varepsilon_{c c}-$ Axial strain in unconfined and confined concrete at the ultimate load point

$\varepsilon_{o l}, \varepsilon_{o h}$ - Longitudinal and circumferential strain in the outer steel tube

$\varepsilon_{i l}$ - Longitudinal strain in the inner steel tube

$\lambda_{E C 4}$ - Non-dimensional slenderness ratio of a member as per EC4

$\lambda_{\text {AISC }}-$ Non-dimensional slenderness ratio of a member as per AISC-360(16)

$v_{o}-$ Strain ratio in a concrete filled steel tube

[12] M. Elchalakani, X.-L. Zhao, and R. Grzebieta, "Tests on concrete filled double-skin (CHS outer and SHS inner) composite short columns under axial compression," Thin-Walled Structures, 2002, vol. 40, no. 5, pp. 415-441.

[13] K. Uenaka, "CFDST stub columns having outer circular and inner square sections under compression," Journal of Constructional Steel Research, 2016, vol. 120, pp. 1-7.

[14] M. F. Hassanein, O. F. Kharoob, and Q. Q. Liang, "Thin-Walled Structures Circular concrete- filled double skin tubular short columns with external stainless steel tubes under axial compression," Thin Walled Structures, 2013, vol. 73, pp. 252-263.

[15] M. F. Hassanein and O. F. Kharoob, "Compressive strength of circular concrete-filled double skin tubular short columns," Thin-Walled Structures, 2014, vol. 77, pp. 165-173.

[16] Y. Essopjee and M. Dundu, "Performance of concrete-filled double-skin circular tubes in compression," Composite Structures, 2015, vol. 133, pp. 1276-1283.

[17] U. M. Sulthana and S. A. Jayachandran, "Axial Compression Behaviour of Long Concrete Filled Double Skinned Steel Tubular Columns," Structures, 2017, vol. 9, pp. 157-164.

[18] T. V. Galambos and A. E. Surovek, Structural Stability of Steel: Concepts and applications for structural engineers. 2008.

[19] ASTM-E8/E8M, "Standard Test Methods for Tension Testing of Metallic Materials," 2009.

[20] IS:516, "Indian Standard methods of tests for strength of concrete," 1959.

[21] L.-H. Han, "Tests on Concrete Filled Steel Tubular Columns with High Slenderness Ratio," Advances in Structural Engineering, 2000, vol. 3, no. 4, pp. 337-344.

[22] T. Perea, "Analytical and Experimental Study on Slender Concrete-Filled Steel Tube Columns and Beam-Columns (PhD Thesis)," Georgia Institute of Technology, 2010.

[23] M. Xiong, D. Xiong, and J. Y. R. Liew, "Behaviour of steel tubular members in fi lled with ultra high strength concrete," Journal of Constructional Steel Research, 2017, vol. 138, pp. $168-183$.

[24] Y.-F. An, L.-H. Han, and X.-L. Zhao, "Behaviour and design calculations on very slender thin-walled CFST columns," Thin-Walled Structures, 2012, vol. 53, pp. 161-175.

[25] T. Perea, R. T. Leon, J. F. Hajjar, and M. D. Denavit, "Full-scale tests of slender concretefilled tubes: Interaction behavior," Journal of Structural Engineering, 2013, vol. 139, no. 7, pp. 1249-1262. 